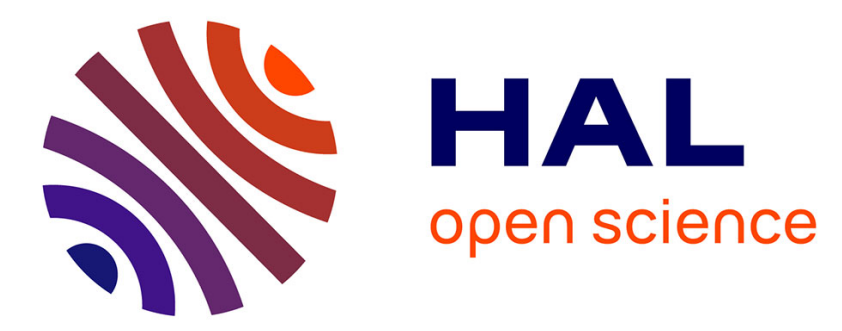

\title{
Luminescent dysprosium single-molecule magnets made from designed chiral BINOL-derived bisphosphate ligands
}

C.A. Mattei, V. Montigaud, V. Dorcet, François Riobé, G. Argouarch, Olivier Maury, Boris Le Guennic, O. Cador, Claudia Lalli, Fabrice Pointillart

\section{To cite this version:}

C.A. Mattei, V. Montigaud, V. Dorcet, François Riobé, G. Argouarch, et al.. Luminescent dysprosium single-molecule magnets made from designed chiral BINOL-derived bisphosphate ligands. Inorganic Chemistry Frontiers, 2021, 8 (4), pp.963-976. 10.1039/d0qi01193b . hal-03164119

\author{
HAL Id: hal-03164119 \\ https://hal.science/hal-03164119
}

Submitted on 30 Mar 2021

HAL is a multi-disciplinary open access archive for the deposit and dissemination of scientific research documents, whether they are published or not. The documents may come from teaching and research institutions in France or abroad, or from public or private research centers.
L'archive ouverte pluridisciplinaire HAL, est destinée au dépôt et à la diffusion de documents scientifiques de niveau recherche, publiés ou non, émanant des établissements d'enseignement et de recherche français ou étrangers, des laboratoires publics ou privés. 


\title{
Luminescent Dysprosium Single-Molecule Magnets Made from Designed Chiral BINOL-Derived Bisphosphate Ligands
}

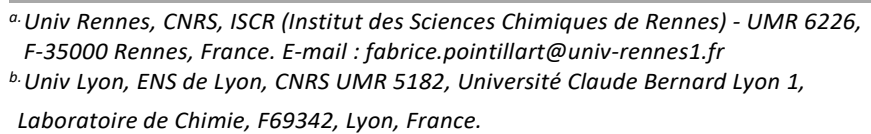

Carlo Andrea Mattei, ${ }^{a}$ Vincent Montigaud, ${ }^{\mathrm{a}}$ Vincent Dorcet, ${ }^{\mathrm{a}}$ François Riobé, ${ }^{\mathrm{b}}$ Gilles Argouarch, Olivier Maury, ${ }^{\mathrm{b}}$ Boris Le Guennic, ${ }^{a}$ Olivier Cador, ${ }^{\mathrm{a}}$ Claudia Lalli, ${ }^{* a}$ Fabrice Pointillart*a

A series of three mono-dimensional polymers $\left[\mathrm{Dy}(\mathrm{hfac})_{3}\left((\boldsymbol{S} / \boldsymbol{R})-\mathbf{L}^{2}\right)\right]_{\mathrm{n}}((\boldsymbol{S} / \boldsymbol{R})-\mathbf{2}),\left[\mathrm{Dy}(\mathrm{hfac})_{3}\left((\boldsymbol{S} / \boldsymbol{R})-\mathrm{L}^{3}\right)\right]_{\mathrm{n}}((\boldsymbol{S} / \boldsymbol{R})-\mathbf{3})$ and $\left[\mathrm{Dy}(\mathrm{hfac})_{3}\left((\boldsymbol{S} / \boldsymbol{R})-\mathrm{L}^{4}\right)\right]_{\mathrm{n}}((\boldsymbol{S} / \boldsymbol{R})-\mathbf{4})$ involving different binaphthyl-2,2'-diyl phosphate ligands $\left((S / R)-L^{2-4}\right)$ were designed from our pioneer reported system of formula $\left[D y(h f a c) 3\left((S / R)-L^{1}\right)\right]_{n}((S /$ $\boldsymbol{R})$-1). The single-crystal X-ray diffraction structures revealed that the final compounds are in their enantiopure form with the ligands bearing the same chirality in the free and coordinated mode. All the polymers can be described as assemblies of mononuclear Single-Molecule Magnets (SMM) in both zero and applied magnetic field. The fitting of the thermal dependence of the relaxation times shown that the magnetic relaxation take place through a combination of thermally activated mechanism (Raman) and Quantum Tunneling of the Magnetization (QTM in zero applied magnetic field). The effect of the nature of the antenna as well as the number of chiral centres of the BINOL-derived bisphosphate ligands on both chiroptical and magnetic properties was studied. Photo-physical and magnetic properties were rationalized by TD-DFT and ab initio calculations. Finally magneto-structural correlations between Dy(III) luminescence, calculations and magnetism were performed.

\section{Introduction}

Molecular objects able to retain their magnetization in a given direction fascinate chemists and physicists since thirty years. This kind of compounds called Single Molecule Magnets ${ }^{1,2}$ (SMMs) display magnetic bistability which has several potential applications in high-density data storage, ${ }^{3}$ quantum computing ${ }^{4}$ and spintronics ${ }^{5}$. On such road, recent significant results were obtained for integrating quantum effects of molecular magnets into devices. ${ }^{4,6-7}$ In the last ten years, the research in the field of SMMs was mainly focused on the employment of lanthanide ions because of their specific magnetic and optical properties. ${ }^{8}$ Their remarkable high magnetic moment and strong anisotropy give rise to the discovery of a new class of mononuclear SMM. ${ }^{9}$ Depending of the strength of the magnetic interaction between the lanthanide-based mononuclear SMM, single Chain Magnet ${ }^{10-13}$ or one-dimensional assembly of mononuclear $\mathrm{SMM}^{14}$ can be obtained. The combination of both magnetic and luminescent properties for one unique $f$ element open new possibilities to obtain multi-properties SMM such as luminescent SMM. ${ }^{15-23}$ When the chirality ingredient is added to the SMM behaviour, chiral $\mathrm{SMM}^{24}$ and ferroelectric $\mathrm{SMM}^{25}$ could be obtained. Finally, when both luminescence and chirality properties are added to the SMM behaviour, rare examples of chiral luminescent $\mathrm{SMM}^{26-29}$ and magneto-chiral $\mathrm{SMM}^{30}$ have been described. Often, the chirality comes from the ligand since organic chemistry offers to the coordination chemists a plethora of chiral ligands, nevertheless their optical activity value is quite limited. In order to obtain higher optical activity, the organic molecular materials propose attractive possibilities with the families of helicenes ${ }^{31}$ and binaphthalene. ${ }^{32}$ The former presents exceptional chiroptical activities provided by a helical scaffold making them good candidates for organic electronics, ${ }^{33}$ chiroptical switches, ${ }^{34}$ chiral $\mathrm{SMM}^{35}$ or singlet oxygen photosensitizers. ${ }^{36}$ Nevertheless, the coordination reactions with these helicene-like compounds are not really developed and the chiral separation is not trivial. ${ }^{31}$ Consequently, we decided to focus our attention on binaphthyl2,2 '-diyl phosphate derivatives. While the corresponding $3 d$ complexes are scarce, ${ }^{37}$ several $4 f$ complexes have been developed for enantioselective Diels-Alder reactions ${ }^{38-42}$ and asymmetric fluorination. ${ }^{43}$ More recently, the luminescence of lanthanide combined with the optical activity of such ligands was exploited for circularly polarized luminescence ${ }^{44-46}$ or for designing chiral luminescent $\mathrm{SMM}^{47-48}$.

Very recently, some of us developed a rational design of mono and tris(binaphtyl)-derived bisphosphate ligands. ${ }^{49}$ The mono-aromatic binaphtyl derived ligand $\left((S / R)-L^{1}\right)$, (Chart 1$)$ was used to build mono-dimensional polymer of formula $\left[\mathrm{Ln}(\mathrm{hfac})_{3}\left((S / R)-\mathrm{L}^{1}\right)\right]_{\mathrm{n}}(\mathrm{Ln}=\mathrm{Dy}, \mathrm{Y}$ and $\mathrm{Eu})$ in solid state and a mononuclear compound in $\mathrm{CH}_{2} \mathrm{Cl}_{2}$ solution $(\mathrm{n}=1) .48$ The dysprosium analogue displayed slow magnetic relaxation in both solid and solution state with a sensitization of the visible luminescence through the $(S / R)-L^{1}$ organic chromophore. 


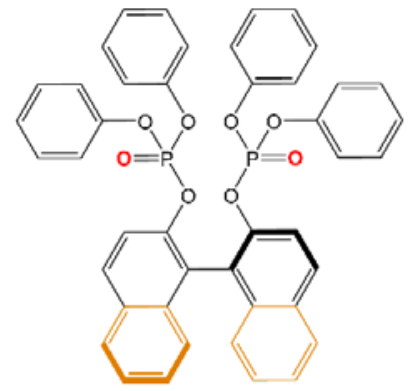

$\left(\mathbf{L}^{1}\right)$

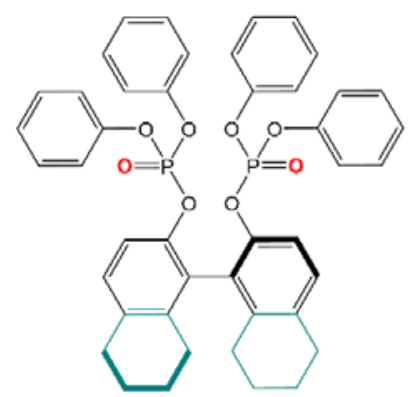

$\left(\mathbf{L}^{3}\right)$

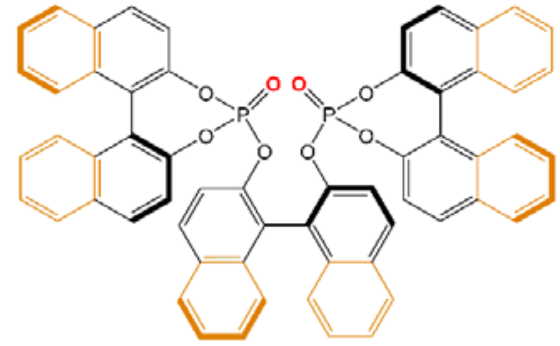

$\left(\mathbf{L}^{2}\right)$

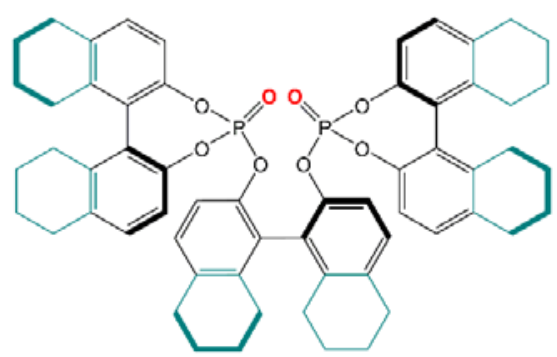

$\left(L^{4}\right)$

Chart 1. Molecular structure of the ligand $(S)-\mathrm{L}^{1-4}$. Orange and turquoise blue colours are used to emphasize the differences between the ligands.

In these lines, we decided to exploit the series of previously designed BINOL-derived bisphosphate ligands to obtain a series of coordination compounds. The number of chiral element was multiplied to give the tris(binaphtyl) analogue of $(S / R)-L^{1}$ called $(S / R)-L^{2}$ (Chart 1$)$, the partial hydrogenation of $(S / R)-L^{1}$ led to $(S / R)-L^{3}$ and finally the combination of both multiplication of the chiral elements and the partial hydrogenation gave $(S / R)-L^{4}$ (Chart 1). One can expect that such structural engineering induced modifications for the chiroptical, emission and magnetic properties. The ligands $(S / R)-L^{1-4}$ were reacted with the Dy (hfac $)_{3} \cdot 2 \mathrm{H}_{2} \mathrm{O}$ precursor to give a series of $1 \mathrm{D}$ polymers of formula $\left[\mathrm{Dy}(\mathrm{hfac})_{3}\left((S / R)-L^{2}\right)\right]_{\mathrm{n}} \quad((S / R)-2), \quad\left[\mathrm{Dy}(\mathrm{hfac})_{3}\left((S / R)-L^{3}\right)\right]_{\mathrm{n}}$ $((S / R)-3)$ and $\left[\mathrm{Dy}(\mathrm{hfac})_{3}\left((S / R)-L^{4}\right)\right]_{\mathrm{n}}((S / R)-4)$. X-ray structures were determined by single crystal diffraction studies. Chiroptical, photophysical and magnetic properties were investigated along the series of compounds and rationalized by computational studies.

\section{Experimental}

\section{Materials and methods}

The precursors Dy $(\mathrm{hfac})_{3} \cdot 2 \mathrm{H}_{2} \mathrm{O} \quad\left(\mathrm{hfac}^{-}=1,1,1,5,5,5-\right.$ hexafluoroacetylacetonate anion), ${ }^{50}(S / R)$ - $\mathrm{L}^{1-4}$ ligand ${ }^{47}$ and the polymer $[(S)-1]_{n}{ }^{48}$ were synthesized following previously reported methods. All other reagents were purchased from Merck Co., Inc. and used without further purification. All solidstate characterizations (elementary analysis, IR, magnetic susceptibility and photophysical measurements) have been done from dried sample and are considered without solvent of crystallization.

Synthesis of the complex $\left\{\left[\mathrm{Dy}(\mathrm{hfac})_{3}((\mathrm{~S})\right.\right.$ $\left.\left.\left.L^{2}\right)\right] \cdot 2\left(\mathrm{C}_{6} \mathrm{H}_{14}\right) \cdot 0.5\left(\mathrm{CH}_{2} \mathrm{Cl}_{2}\right)\right\}_{n}\left(\left\{[(S)-2] \cdot 2\left(\mathrm{C}_{6} \mathrm{H}_{14}\right) \cdot 0.5\left(\mathrm{CH}_{2} \mathrm{Cl}_{2}\right)\right\}_{n}\right)$ and $\left\{\left[\mathrm{Dy}(\mathrm{hfac})_{3}\left((\boldsymbol{R})-\mathrm{L}^{2}\right)\right] \cdot 2\left(\mathrm{C}_{6} \mathrm{H}_{14}\right)\right\}_{\mathrm{n}}\left(\left\{[(R)-2] \cdot 2\left(\mathrm{C}_{6} \mathrm{H}_{14}\right)\right\}_{\mathrm{n}}\right) .49 .2 \mathrm{mg}$ of Dy $(\mathrm{hfac})_{3} \cdot 2 \mathrm{H}_{2} \mathrm{O}(0.06 \mathrm{mmol})$ were dissolved in $5 \mathrm{~mL}$ of $\mathrm{CH}_{2} \mathrm{Cl}_{2}$ and then added to a solution of $5 \mathrm{~mL}$ of $\mathrm{CH}_{2} \mathrm{Cl}_{2}$ containing 56.8 $\mathrm{mg}$ of $(S / R)-\mathrm{L}^{2}(0.06 \mathrm{mmol})$. After 15 minutes of stirring, $30 \mathrm{~mL}$ of $n$-hexane were layered. Slow diffusion led to colorless single crystals which were suitable for X-ray studies. Yield $90.8 \mathrm{mg}(88$ $\%)$ for $[(S)-2]_{n}$ and $87.6 \mathrm{mg}(84 \%)$ for [(R)-2 $]_{n}$. Anal. Calcd (\%) for [(S)-2 $]_{\mathrm{n}} \mathrm{C}_{75} \mathrm{H}_{39} \mathrm{DyF}_{18} \mathrm{O}_{14} \mathrm{P}_{2}$ : C 52.04, $\mathrm{H}$ 2.25; found: $\mathrm{C} 52.31, \mathrm{H}$ 2.36. Anal. Calcd (\%) for $[(R)-2]_{n} C_{75} \mathrm{H}_{39} \mathrm{DyF}_{18} \mathrm{O}_{14} \mathrm{P}_{2}$ : C 52.04, $\mathrm{H}$ 2.25; found: $\mathrm{C} 52.22, \mathrm{H}$ 2.30. I.R. ( $\mathrm{KBr}$, range $3200-400 \mathrm{~cm}^{-1}$ ) for [(S)-2 $]_{\mathrm{n}}: 3139(\mathrm{w}), 3016(\mathrm{w}), 1653(\mathrm{~s}), 1592(\mathrm{w}), 1557(\mathrm{~m})$, $1529(\mathrm{w}), 1506(\mathrm{~m}), 1466(\mathrm{~m}), 1256(\mathrm{~s}), 1203(\mathrm{~s}), 1147(\mathrm{~s}), 1072$ (m), $1037(\mathrm{~m}), 1015(\mathrm{~m}), 972(\mathrm{~m}), 898(\mathrm{w}), 749(\mathrm{w}), 661(\mathrm{~m})$ and $566(w) \mathrm{cm}^{-1}$ and for $[(R)-2]_{\mathrm{n}}: 3140(\mathrm{w}), 3016(\mathrm{w}), 1652(\mathrm{~s}), 1589$ $(\mathrm{w}), 1555(\mathrm{~m}), 1529(\mathrm{w}), 1506(\mathrm{~m}), 1465(\mathrm{~m}), 1258(\mathrm{~s}), 1205(\mathrm{~s})$, $1147(\mathrm{~s}), 1073(\mathrm{~m}), 1036(\mathrm{~m}), 1011(\mathrm{~m}), 970(\mathrm{~m}), 900(\mathrm{w}), 748$ (w), $660(\mathrm{~m})$ and $563(\mathrm{w}) \mathrm{cm}^{-1}$

Synthesis of the complex $\left[\mathrm{Dy}(\mathrm{hfac})_{3}\left((S / R)-L^{3}\right)\right]_{\mathrm{n}}\left([(S / R)-3]_{\mathrm{n}}\right)$. $32.8 \mathrm{mg}$ of $\mathrm{Dy}(\mathrm{hfac})_{3} \cdot 2 \mathrm{H}_{2} \mathrm{O}(0.04 \mathrm{mmol})$ was added into a solution of $30.3 \mathrm{mg}$ of $(\mathrm{S} / R)-\mathrm{L}^{3}(0.04 \mathrm{mmol})$ in $4 \mathrm{~mL}$ of $\left(\mathrm{CH}_{2}\right)_{2} \mathrm{Cl}_{2}$ and stirred for 15 minutes. Slow evaporation led to a colorless microcrystalline residue. Yield $54.0 \mathrm{mg}(88 \%)$ for $[(S)-3]_{\mathrm{n}}$ and $46.3 \mathrm{mg}(75 \%)$ for $[(\boldsymbol{R})-3]_{\mathrm{n}}$. Slow evaporation from a solution of $\mathrm{CH}_{2} \mathrm{Cl}_{2} / n$-hexane led to single crystals suitable for $\mathrm{X}$-ray studies. Anal. Calcd (\%) for [(S)-3 $]_{n}, \mathrm{C}_{59} \mathrm{H}_{43} \mathrm{DyF}_{18} \mathrm{O}_{14} \mathrm{P}_{2}$ : C 45.90, H 2.79; found: $\mathrm{C} 45.82, \mathrm{H}$ 2.94. I.R. ( $\mathrm{KBr}$, range $3200-400 \mathrm{~cm}^{-1}$ ): 3139 
(w), $3067(w), 2938(w), 2882(w), 1654(s), 1555(m), 1527(m)$, 1490 (s), 1256 (s), 1201 (s), $1146(\mathrm{~s}), 1074(\mathrm{~m}), 1027(\mathrm{~m}), 1018$ $(\mathrm{m}), 903(\mathrm{w}), 797(\mathrm{~m}), 754(\mathrm{~m}), 661(\mathrm{~m})$ and $564(\mathrm{w}) \mathrm{cm}^{-1}$. Anal. Calcd (\%) for [(R)-3], $\mathrm{C}_{59} \mathrm{H}_{43} \mathrm{DyF}_{18} \mathrm{O}_{14} \mathrm{P}_{2}$ : C 45.90, $\mathrm{H}$ 2.79; found: C 45.88, H 2.91. I.R. ( $\mathrm{KBr}$, range $3200-400 \mathrm{~cm}^{-1}$ ): 3135 (w), 3067 (w), 2938 (w), $2880(w), 1650(\mathrm{~s}), 1557(\mathrm{~m}), 1529(\mathrm{~m}), 1487$ (s), $1255(\mathrm{~s}), 1199(\mathrm{~s}), 1146(\mathrm{~s}), 1074(\mathrm{~m}), 1027(\mathrm{~m}), 1020(\mathrm{~m})$, $899(\mathrm{w}), 801(\mathrm{~m}), 755(\mathrm{~m}), 661(\mathrm{~m})$ and $564(\mathrm{w}) \mathrm{cm}^{-1}$.

Synthesis of the complex $\left[\mathrm{Dy}(\mathrm{hfac})_{3}\left((S / R)-L^{4}\right)\right]_{\mathrm{n}}\left([(S / R)-4]_{\mathrm{n}}\right)$. $58.3 \mathrm{mg}$ of $(S / R)-\mathrm{L}^{4}(0.06 \mathrm{mmol})$ were dissolved in $5 \mathrm{~mL}$ of toluene and added into a suspension of $49.2 \mathrm{mg}$ of $\mathrm{Dy}(\mathrm{hfac})_{3}$ $2 \mathrm{H}_{2} \mathrm{O}(0.06 \mathrm{mmol})$ in $3 \mathrm{~mL}$ of toluene. The resulting solution was stirred for 15 minutes. Slow diffusion of $n$-pentane led to colorless single crystals which were suitable for X-ray studies. Yield $86.9 \mathrm{mg}(83 \%)$ for $[(S)-4]_{\mathrm{n}}$ and $94.0 \mathrm{mg}(89 \%)$ for $[(\boldsymbol{R})-4]_{\mathrm{n}}$. Anal. Calcd (\%) for [(S)-4 $]_{n}, \mathrm{C}_{75} \mathrm{H}_{63} \mathrm{DyF}_{18} \mathrm{O}_{14} \mathrm{P}_{2}$ : C 51.33, H 3.59; found: C 51.35, H 3.71. I.R. ( $\mathrm{KBr}$, range $\left.3200-400 \mathrm{~cm}^{-1}\right): 2939$ $(\mathrm{m}), 2863(\mathrm{w}), 1655(\mathrm{~s}), 1555(\mathrm{w}), 1501(\mathrm{~m}), 1469(\mathrm{~m}), 1256(\mathrm{~s})$, 1206 (s), 1147 (s), 1075 (w), $1056(\mathrm{~m}), 1018(\mathrm{~m}), 993(\mathrm{~m}), 891$ (w), 661 (w) and $562(\mathrm{w}) \mathrm{cm}^{-1}$. Anal. Calcd (\%) for [(R)-4] $\mathrm{C}_{75} \mathrm{H}_{63} \mathrm{DyF}_{18} \mathrm{O}_{14} \mathrm{P}_{2}$ : C 51.33, H 3.59; found: C 51.39, H 3.69. I.R. $\left(\mathrm{KBr}\right.$, range $\left.3200-400 \mathrm{~cm}^{-1}\right)$ : $2940(\mathrm{~m}), 2863(\mathrm{w}), 1651(\mathrm{~s}), 1552$ $(\mathrm{w}), 1499(\mathrm{~m}), 1469(\mathrm{~m}), 1255(\mathrm{~s}), 1201(\mathrm{~s}), 1145(\mathrm{~s}), 1078(\mathrm{w})$, $1056(\mathrm{~m}), 1018(\mathrm{~m}), 989(\mathrm{~m}), 891(\mathrm{w}), 660(\mathrm{w})$ and $562(\mathrm{w}) \mathrm{cm}^{-1}$. The $Y$ analogues of $[(S)-2]_{n}[(S)-3]_{n}$ and $[(S)-4]_{n}$ respectively named $[(S)-(Y)-2]_{n}[(S)-(Y)-3]_{n}$ and $[(S)-(Y)-4]_{n}$ were synthetized using the same protocol than for their dysprosium analogues. Yields $71.6 \mathrm{mg}(72 \%)$ for $[(S)-(Y)-2]_{\mathrm{n}}$, Anal. Calcd (\%) $\mathrm{C}_{75} \mathrm{H}_{39} \mathrm{YF}_{18} \mathrm{O}_{14} \mathrm{P}_{2}$ : C 54.35, H 2.36; found: C 54.22, H 2.40.; I.R. $\left(\mathrm{KBr}\right.$, range $\left.3200-400 \mathrm{~cm}^{-1}\right): 3136(\mathrm{w}), 3011(\mathrm{w}), 1652(\mathrm{~s}), 1592$ (w), $1557(\mathrm{~m}), 1529(\mathrm{w}), 1504(\mathrm{~m}), 1466(\mathrm{~m}), 1256(\mathrm{~s}), 1205(\mathrm{~s})$, $1150(\mathrm{~s}), 1071(\mathrm{~m}), 1037(\mathrm{~m}), 1014(\mathrm{~m}), 972(\mathrm{~m}), 900(\mathrm{w}), 750$ (w), $661(\mathrm{~m})$ and $568(\mathrm{w}) \mathrm{cm}^{-1}$ for, $45.2 \mathrm{mg}$ (77\%) for [(S)-(Y)3] n, Anal. Calcd (\%) $\mathrm{C}_{59} \mathrm{H}_{43} \mathrm{YF}_{18} \mathrm{O}_{14} \mathrm{P}_{2}$ : $\mathrm{C} 50.94, \mathrm{H}$ 3.09; found: $\mathrm{C}$ 51.02, H 3.10.; I.R. ( $\mathrm{KBr}$, range $\left.3200-400 \mathrm{~cm}^{-1}\right)$ : 3136 (w), 3009 (w), $1650(\mathrm{~s}), 1592(\mathrm{w}), 1557(\mathrm{~m}), 1530(\mathrm{w}), 1504(\mathrm{~m}), 1466(\mathrm{~m})$, 1253 (s), 1207 (s), 1150 (s), $1071(\mathrm{~m}), 1035$ (m), $1014(\mathrm{~m}), 970$ $(\mathrm{m}), 900(\mathrm{w}), 748(\mathrm{w}), 660(\mathrm{~m})$ and $570(\mathrm{w}) \mathrm{cm}^{-1}$ and $79.9 \mathrm{mg}(79$ \%) for [(S)-(Y)-4] $]_{n}$, Anal. Calcd (\%) for $\mathrm{C}_{75} \mathrm{H}_{63} \mathrm{YF}_{18} \mathrm{O}_{14} \mathrm{P}_{2}: \mathrm{C} 53.57$, H 3.75; found: C 53.42, H 3.90.; I.R. (KBr, range $3200-400 \mathrm{~cm}$ 1): $3136(w), 3011(w), 1652(s), 1592(w), 1557(m), 1529(w)$, $1504(\mathrm{~m}), 1466(\mathrm{~m}), 1256(\mathrm{~s}), 1205(\mathrm{~s}), 1150(\mathrm{~s}), 1071(\mathrm{~m}), 1037$ $(\mathrm{m}), 1014(\mathrm{~m}), 972(\mathrm{~m}), 900(\mathrm{w}), 750(\mathrm{w}), 661(\mathrm{~m})$ and $568(\mathrm{w})$ $\mathrm{cm}^{-1}$.

\section{Single crystal $X$-ray structure analysis}

Single crystals of $[(\boldsymbol{S} / \boldsymbol{R})-2]_{n},[(\boldsymbol{S})-3]_{n}$ and $[(\boldsymbol{S})-4]_{n}$ were mounted on a APEXIII D8 VENTURE Bruker-AXS diffractometer for data collection (MoK $\alpha$ radiation source, $\lambda=0.71073 \AA$ ), from the Centre de Diffractométrie (CDIFX), Université de Rennes 1, France. Structure was solved with a direct method using the SHELXT program ${ }^{51}$ and refined with a full matrix least-squares method on $\mathrm{F}^{2}$ using the SHELXL-14/7 program $^{52}$. A SQUEEZE procedure of PLATON ${ }^{53}$ was performed as the structures for $[(S / R)-2]_{n}$ and $[(S)-4]_{n}$ contains large solvent accessible voids in which residual peaks of diffraction were observed. It is worth to notice that due to the quality of the single crystal and/or the fast loss of solvent molecules of crystallization, a mediocre level of refinement was obtained for $[(\boldsymbol{R})-\mathbf{2}]_{\mathrm{n}}$ and $[(\boldsymbol{S})-3]_{\mathrm{n}}$ despite all our efforts. Crystallographic data are summarized in Table S1. Complete crystal structure results as a CIF files (CCDC 19944561994459) including bond lengths, angles, and atomic coordinates are deposited as Supporting Information. X-ray diffraction (XRD) patterns were recorded at room temperature in the $2 \theta$ range $5-30^{\circ}$ with a step size of $0.026^{\circ}$ and a scan time per step of $600 \mathrm{~s}$ using a PANalytical X'Pert Pro diffractometer (Cu-L2,L3 radiation, $\lambda=1.5418 \AA, 40 \mathrm{kV}, 40 \mathrm{~mA}$, PIXcel 1D detector). Data collector and HighScore Plus softwares were used, respectively, for recording and analysis of the patterns.

\section{Physical Measurements}

The elementary analyses of the compounds were performed at the Centre Régional de Mesures Physiques de l'Ouest, Rennes. Absorption spectra were recorded on a JASCO V-650 spectrophotometer in diluted solution, using spectrophotometric grade solvents. Electronic circular dichroism (ECD) was measured on a Jasco J-815 Circular Dichroism Spectrometer (IFR140 facility - Biosit- Université de Rennes 1). Emission spectra were measured using HoribaJobin-Yvon Fluorolog-3 fluorimeter. The steady-state luminescence was excited by unpolarised light from a $450 \mathrm{~W}$ xenon continuous wave (CW) lamp and detected at an angle of $90^{\circ}$ by using a Hamamatsu R928 PMT. Solid samples were placed in $4 \mathrm{~mm}$ quartz tubes and set into an Oxford Instrument cryostat (Optistat CF2) insert directly in the sample chamber of the spectrofluorimeter. The dc magnetic susceptibility measurements were performed on solid polycrystalline sample with a Quantum Design MPMS-XL SQUID magnetometer between 2 and $300 \mathrm{~K}$ in applied magnetic field of $0.02 \mathrm{~T}$ for temperatures of $2-20 \mathrm{~K}, 0.2 \mathrm{~T}$ for temperature of $20-80 \mathrm{~K}$ and $1 \mathrm{~T}$ for temperatures of $80-300 \mathrm{~K}$. The ac magnetic susceptibility measurements were performed on a Quantum Design MPMSXL SQUID for frequencies between 1 and $1000 \mathrm{~Hz}$ and a Quantum Design PPMS magnetometers for frequencies between 50 and $10000 \mathrm{~Hz}$. These measurements were all corrected for the diamagnetic contribution as calculated with Pascal's constants.

Computational details. DFT geometry optimizations and TDDFT excitation energy calculations of the ligand $(S)-L^{2-4}$ were carried out with the Gaussian 09 (revision A.02) package ${ }^{54}$ employing the PBEO hybrid functional. ${ }^{55,56}$ All atoms were described with the SVP basis sets. ${ }^{57}$ In the TD-DFT calculations, The first 50 monoelectronic excitations were calculated. In all steps, a modelling of bulk solvent effects (solvent = dichloromethane) was included through the Polarizable Continuum Model (PCM), 58 using a linear-response nonequilibrium approach for the TD-DFT step. ${ }^{59,60}$ The atomic positions were extracted from the $\mathrm{X}$-ray crystal structure of $\left\{[(S)-2] \cdot 2\left(\mathrm{C}_{6} \mathrm{H}_{14}\right) \cdot 0.5\left(\mathrm{CH}_{2} \mathrm{Cl}_{2}\right)\right\}_{n},[(S)-3]_{n}$ and $[(S)-4]_{n}$ and only one Dy(III) was taken into account $(n=1)$. The optimization of the hydrogen and fluorine positions, while other atomic positions were kept frozen, have been carried out on the $Y^{\prime \prime \prime}$ parent molecule by Density Functional Theory (DFT) as implemented in the Gaussian 09 (revision D.01) package ${ }^{54}$ using the PBEO hybrid functional. 55,56 The "Stuttgart/Dresden" basis sets and effective core potentials were used to describe the yttrium 
atom ${ }^{61}$ while other atoms were described with the SVP basis sets. ${ }^{57}$ The wavefunction theory calculations (WFT) were carried out with the help of the OpenMolcas software package. ${ }^{62}$ In these calculations, the complete active space self-consistent field $^{63}$ (CASSCF) approach was used to treat the static correlation effects arising from the partially filled $4 f$ shell of the Dy(III) ion. The second-order Douglas-Kroll-Hess ${ }^{64-65}$ scalar relativistic (SR) Hamiltonian was used to treat the scalar relativistic effects in combination with the all-electron atomic natural orbital relativistically contracted (ANO-RCC) basis sets from the OpenMolcas library. ${ }^{68-70}$ The basis sets were contracted to the triple- $\zeta$ plus polarization (TZP) quality for the Dy, $\mathrm{P}$ and $\mathrm{O}$ atoms bonded to the lanthanide (Dy = 25s22p15d11f4g2h/8s7p4d3f2g1h; $P=$ $17 \mathrm{~s} 12 \mathrm{p} 5 \mathrm{~d} 4 \mathrm{f} 2 \mathrm{~g} / 5 \mathrm{~s} 4 \mathrm{p} 2 \mathrm{~d} 1 \mathrm{f} ; \mathrm{O}=14 \mathrm{~s} 9 \mathrm{p} 5 \mathrm{~d} 3 \mathrm{f} 2 \mathrm{~g} / 4 \mathrm{~s} 3 \mathrm{p} 2 \mathrm{~d} 1 \mathrm{f}$ ), and to the double- $\zeta$ quality for the rest of the $\mathrm{O}$ atoms and $\mathrm{H}, \mathrm{C}$ and $\mathrm{F}$ atoms $(H=8 s 4 p 3 d 1 f / 2 s, \quad C=14 s 9 p 5 d 3 f 2 g / 3 s 2 p, \quad F=$ $14 s 9 p 5 d 3 f 2 g / 3 s 2 p)$. The calculations employed the stateaveraged formalism at the SR level by taking into account the 21 sextet, the 224 quartet and the 490 doublet spin states arising from the 9 electrons spanning the seven $4 f$ orbitals (i.e. $\mathrm{CAS}(9,7)$ ). The spin-orbit coupling (SOC) was then introduced within a state interaction among the basis of calculated SR states using the restricted active space state interaction (RASSI) approach. ${ }^{71}$ Herein the SOC matrix is diagonalized using the calculated 21 SR sextet, 224 SR quartet and the $98^{\text {th }}$ lowest SR doublet spin states. The EPR $g$-factors were calculated according to Reference 72 as implemented in the RASSI module of OpenMolcas, whereas the magnetic susceptibility and magnetization calculations were performed using the SingleAniso module of OpenMolcas as detailed in Reference 73.

\section{Results and discussions}

\section{Structural description}

$\left\{\left[\text { Dy }(\text { hfac })_{3}\left(S-\mathrm{L}^{2}\right)\right] \cdot 0.5\left(\mathrm{CH}_{2} \mathrm{Cl}_{2}\right) \cdot 2\left(\mathrm{C}_{6} \mathrm{H}_{14}\right)\right\}_{\mathrm{n}}$

$\{[(S)-$

$\left.2] \cdot 2\left(\mathrm{C}_{6} \mathrm{H}_{14}\right) \cdot 0.5\left(\mathrm{CH}_{2} \mathrm{Cl}_{2}\right)\right\}_{\mathrm{n}}$ and $\left\{\left[\mathrm{Dy}(\mathrm{hfac})_{3}\left((R)-\mathrm{L}^{2}\right)\right] \cdot 2\left(\mathrm{C}_{6} \mathrm{H}_{14}\right)\right\}_{\mathrm{n}}$ $\left\{[(\boldsymbol{R})-\mathbf{2}] \cdot \mathbf{2}\left(\mathrm{C}_{6} \mathrm{H}_{14}\right)\right\}_{\mathrm{n}}$. The crystalline structures of the two enantiomers are similar and thus only the structure of $\{[(S)$ 2] $\left.\cdot 2\left(\mathrm{C}_{6} \mathrm{H}_{14}\right) \cdot \mathbf{0 . 5}\left(\mathrm{CH}_{2} \mathrm{Cl}_{2}\right)\right\}_{\mathrm{n}}$ will be described in the following lines with numerical data for $\left\{[(\boldsymbol{R})-\mathbf{2}] \cdot \mathbf{2}\left(\mathbf{C}_{6} \mathbf{H}_{14}\right)\right\}_{n}$ given between brackets. $\left\{[(S)-2] \cdot \mathbf{2}\left(\mathrm{C}_{6} \mathrm{H}_{14}\right) \cdot \mathbf{0 . 5}\left(\mathrm{CH}_{\mathbf{2}} \mathrm{Cl}_{2}\right)\right\}_{\mathrm{n}}$ crystallizes in the $\mathrm{P} 2{ }_{1} 2_{1} 2_{1}\left(\mathrm{~N}^{\circ} 19\right)$ chiral orthorhombic space group (Table S1) and its asymmetric unit is composed of one $(S)-L^{2}$ ligand, one Dy(hfac $)_{3}$ moiety, two n-hexane and a half dichloromethane interstitial solvent molecules (Figs. S1 and S2). The Dy (hfac) moieties are linked by the $(S)-L^{2}$ ligands through the $P=O$ groups to form an almost linear one-dimensional structure (Fig. 1).

The Dy(III) ion is surrounded by eight oxygen atoms coming from three hfac ${ }^{-}$anions and two $\mathrm{P}=\mathrm{O}$ groups. The arrangement of the ligands leads to an almost perfect square antiprism $\left(D_{4 d}\right.$ symmetry) coordination polyhedron from SHAPE (CShM ${ }_{S A P R-8}=$ 0.142 [0.221]) analysis. ${ }^{74}$ Both Dy-Ohfac $(2.344(11) \AA ̊ n)$ $\left[2.336(17)^{\circ}\right]$ and $\mathrm{Dy}-\mathrm{O}_{\mathrm{P}=\mathrm{O}}$ bond lengths $(2.341(10) \AA$ ) $\left[2.353(15)^{\circ}\right]$ are found similar. The $\mathrm{P}=0 \mathrm{O}-\mathrm{Dy}-\mathrm{O}_{\mathrm{P}=\mathrm{O}}$ angle was found equal to $139.99(8)^{\circ}\left[139.61(8)^{\circ}\right]$.
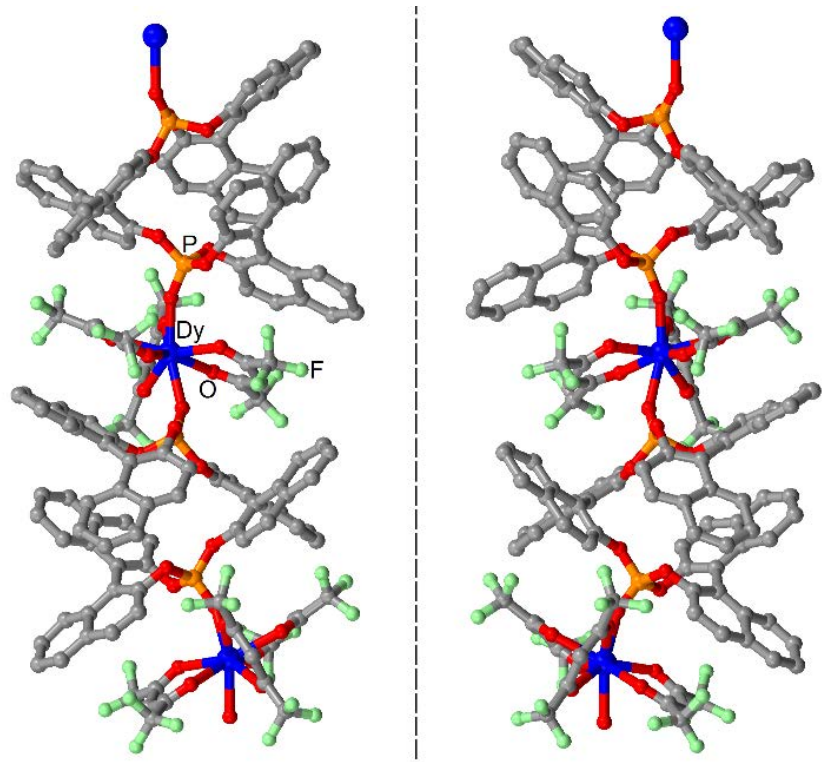

Fig. 1 Molecular structures of the one-dimensional polymers $\left[\mathrm{Dy}(\mathrm{hfac})_{3}\left((S)-\mathrm{L}^{2}\right)\right]_{\mathrm{n}}[(S)-2]_{\mathrm{n}}$ (left) and $\left[\mathrm{Dy}(\mathrm{hfac})_{3}\left((R)-\mathrm{L}^{2}\right)\right]_{\mathrm{n}}[(\boldsymbol{R})-2]_{\mathrm{n}}$. Hydrogen atoms and solvent molecules are omitted for clarity.

The dihedral angles between the planes formed by the naphtyl groups are also found similar for the two external binaphtyl fragments with values of $61.2(3)^{\circ}\left[61.4^{\circ}\right]$ and $59.1(3)^{\circ}\left[59.1(4)^{\circ}\right]$ which are weaker than the dihedral angle value found for the central binaphtyl fragment $78.7(2)^{\circ}\left[79.4(3)^{\circ}\right]$. The intra-chain Dy-Dy distances are found equal to 12.893(2) $\AA$ [12.966(2)]. The crystal packing (Fig. S4) highlights both $\pi$ - $\mathrm{CH}$ interactions and $\mathrm{F}$... H contacts to assume the cohesion of the crystal but no $\pi-\pi$ stacking has been found. The shortest inter-chain Dy-Dy distances are found equal to $12.850(2) \AA$ [12.836(2)] which is in the same order of magnitude than the shortest intramolecular Dy-Dy distance.

$\left[\mathrm{Dy}(\mathbf{h f a c})_{3}\left((S)-\mathrm{L}^{3}\right)\right]_{\mathrm{n}}[(\boldsymbol{S})-3]_{\mathrm{n}}:[(S)-3]_{\mathrm{n}}$ crystallizes in the $\mathrm{P} 3_{1} 12$ $\left(N^{\circ} 151\right)$ chiral trigonal space group (Table S1) and its asymmetric unit is composed of one half $(S)$ - $L^{3}$ ligand and one half Dy(hfac) $)_{3}$ moiety (Fig. S4). The coordination mode is very similar to the one observed for $[(S)-2]_{n}$ leading to the formation of a mono-dimensional polymer (Fig. 2) in which the Dy(III) centre is in a $\mathrm{D}_{4 \mathrm{~d}}$ coordination mode $\left(\mathrm{CShM}_{\mathrm{SAPR}-8}=0.310\right)$ (Table S2). ${ }^{74}$ The Dy- $\mathrm{O}_{\mathrm{hfac}}\left(2.344(12) \AA\right.$ ) are longer than the $\mathrm{Dy}-\mathrm{O}_{\mathrm{P}=\mathrm{O}}$ bond lengths $(2.295(11) \AA$ ).

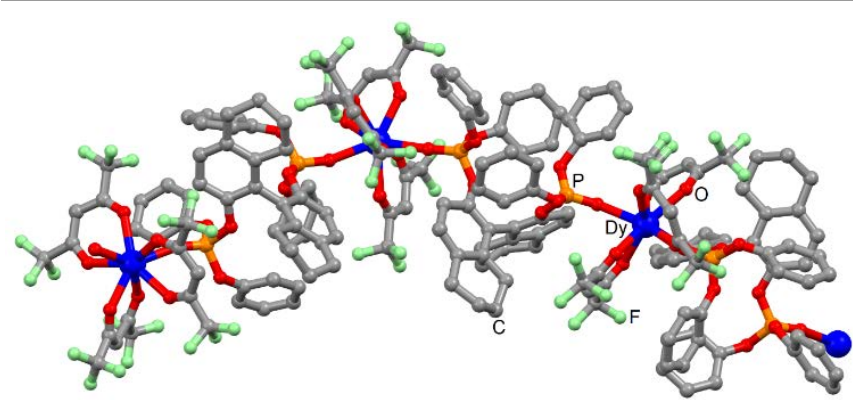

Fig. 2 Molecular structure of the one-dimensional polymer $\left[\operatorname{Dy}(\mathrm{hfac})_{3}\left((S)-L^{3}\right)\right]_{n}[(S)-3]_{n}$ 


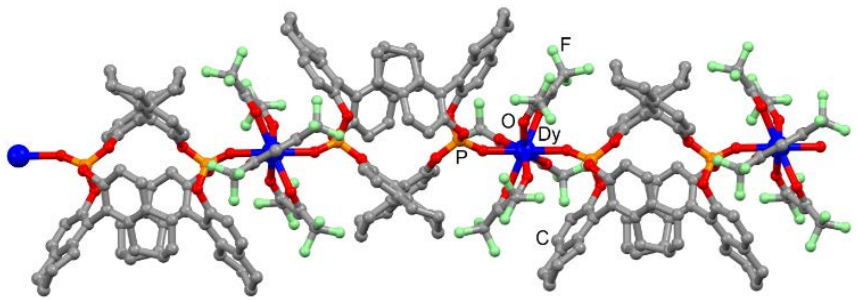
Fig. 3 Molecular structure of the one-dimensional polymer $\left[\mathrm{Dy}(\mathrm{hfac})_{3}\left((S)-\mathrm{L}^{4}\right)\right]_{n}[(S)-$
$4]_{n}$.

The $\mathrm{P}=\mathrm{O} O-\mathrm{Dy}-\mathrm{O}_{\mathrm{P}=\mathrm{O}}$ angle was found equal to $143.29(6)^{\circ}$ and the relative arrangement of the ligands led to a non-linear coordination polymer. The two naphtyl-like systems are perpendicular (dihedral angle of $90^{\circ}$ ) for symmetry reason. The intra-chain Dy-Dy distances are found equal to $12.617(2) \AA$.

The cohesion of the crystal packing is assumed by both $\pi-\mathrm{CH}$ interactions and $\mathrm{F} \cdots \mathrm{H}$ contacts without $\pi-\pi$ stacking (Fig. S5). The shortest inter-chain Dy-Dy distances are found equal to 12.544(4) A which is in the same order of magnitude than the shortest intramolecular Dy-Dy distance.

$\left[\mathrm{Dy}(\mathrm{hfac})_{3}\left((S)-\mathrm{L}^{4}\right)\right]_{\mathrm{n}}[(S)-4]_{\mathrm{n}}:[(S)-4]_{\mathrm{n}}$ crystallizes in the $\mathrm{P} 4_{1} 22$ $\left(\mathrm{N}^{\circ} 91\right)$ chiral tetragonal space group (Table $\left.\mathrm{S} 1\right)$ and its asymmetric unit is composed of one half $(S)$ - $L^{4}$ ligand and one half $\mathrm{Dy}(\mathrm{hfac})_{3}$ moiety (Fig. S6). The 08 coordination sphere around the Dy(III) adopted a slightly distorted $\mathrm{D}_{4 \mathrm{~d}}$ symmetry $\left(\right.$ CShM $\left._{\text {SAPR- } 8}=0.230\right)\left(\right.$ Table S2).$^{74}$ The Dy-O ${ }_{\text {hfac }}(2.315(12) \AA)$ are longer than the $\mathrm{Dy}-\mathrm{O}_{\mathrm{P}=\mathrm{O}}$ bond lengths $(2.278(9) \AA)$. The $\mathrm{P=O}$ O-Dy$\mathrm{O}_{\mathrm{P}=\mathrm{O}}$ angle was found equal to $145.06(5)^{\circ}$ and the arrangement of the ligands led to an almost linear coordination polymer (Figure 3 ). The dihedral angles of the three binaphtyl groups are $66.8(4)^{\circ}, 74.8(3)^{\circ}$ and $66.8(3)^{\circ}$ with the obtuse angle corresponding to the central binaphtyl group. The intra-chain Dy-Dy distances are found equal to 13.236(2) ̊. As for the two $[(\boldsymbol{S} / \boldsymbol{R})-\mathbf{2}]_{\mathrm{n}}$ and $[(\boldsymbol{S})-3]_{\mathrm{n}}$ coordination polymers, the cohesion of the crystal packing is assumed by both $\pi-\mathrm{CH}$ interactions and $\mathrm{F} \cdots \mathrm{H}$ contacts without $\pi-\pi$ stacking (Fig. S7). The shortest interchain Dy-Dy distances are found equal to 13.236(4) $\AA$ that is in the same order of magnitude than the shortest intramolecular Dy-Dy distance.

The analysis of the four X-ray structures showed that the Dy-O bond lengths are all similar when the binaphtyl moieties are fully aromatic $\left([(S)-1]_{n}{ }^{48}\right.$ and $\left.[(S / R)-2]_{n}\right)$ while the Dy- $O_{\mathrm{P}=\mathrm{O}}$ bond lengths are shorter than the Dy- $\mathrm{O}_{\mathrm{hfac}}$ bond lengths when the binaphtyl moieties are partially hydrogenated $\left([(\boldsymbol{S})-3]_{n}\right.$ and $[(\boldsymbol{S})$ $\left.4]_{n}\right)$. Nevertheless, for all the compounds the coordination sphere of the Dy(III) centre adopted an almost perfect $D_{4 d}$ symmetry. The $\mathrm{P}=\mathrm{O} O-\mathrm{Dy}-\mathrm{O}_{\mathrm{P}=\mathrm{O}}$ angles are very close with values ranging from $139.6^{\circ}$ to $145.4^{\circ}$. The dihedral angle of the binaphtyl moieties range from $74.8^{\circ}$ to $79.4^{\circ}$ for ligands involving only one binaphtyl moiety $\left(L^{1}\right)$ and for the central binaphtyl moiety in case of $\mathrm{L}^{2}$ and $\mathrm{L}^{4}$. For the external binaphtyl moieties in $L^{2}$ and $L^{4}$, the torsion angle values range from $59.1^{\circ}$ to $66.8^{\circ}$. An exception is observed for $[(S)-3]_{n}$ since the torsion angle value is imposed to $90^{\circ}$ because of the symmetry of the space group and might be the origin of the formation of a nonlinear polymer while the others are linear.
The purity phase for all the samples was checked by powder $\mathrm{X}$-ray diffraction. Fast loss of crystallographic solvent molecules led to a loss of crystallinity of the powder for $\{[(S)$ $\left.2] \cdot 2\left(\mathrm{C}_{6} \mathrm{H}_{14}\right) \cdot 0.5\left(\mathrm{CH}_{2} \mathrm{Cl}_{2}\right)\right\}_{n},\left\{[(R)-2] \cdot 2\left(\mathrm{C}_{6} \mathrm{H}_{14}\right)\right\}_{n}$ and $[(S)-4]_{n}$ (Figs. $\mathrm{S} 8-\mathrm{S} 10)$.

\section{Magnetic Properties}

\section{Static measurements.}

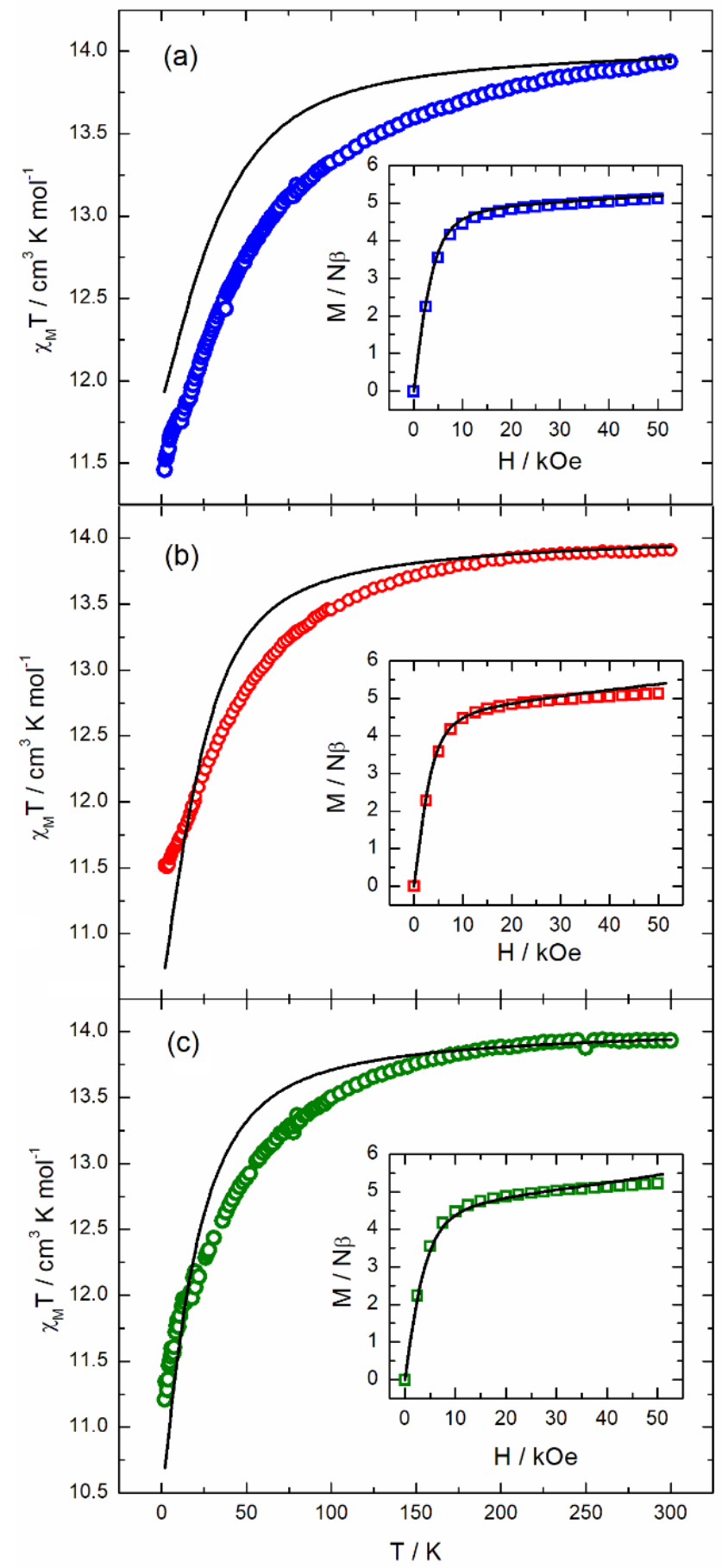

Fig. 4 Thermal dependence of $\chi_{M} T$ for (a) $[(S)-2]_{n}$ (blue circles), (b) [(S)-3 $]_{n}$ (red circles) and (c) $[(S)-4]_{n}$ (green circles). Inset: field variation of the magnetization measured at 2

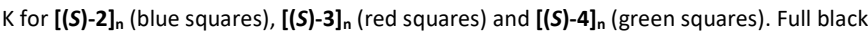
lines correspond to the ab initio computational results (see text for details). 
The experimental temperature dependence of $\chi_{M} T$ for compound $[(S)-2]_{n},[(S)-3]_{n}$ and $[(S)-4]_{n}$ are represented on Fig. 4. Room temperature values $\left(13.94 \mathrm{~cm}^{3} \mathrm{~K} \mathrm{~mol}^{-1}, 13.91 \mathrm{~cm}^{3} \mathrm{~K}\right.$ $\mathrm{mol}^{-1}$ and $13.93 \mathrm{~cm}^{3} \mathrm{~K} \mathrm{~mol}^{-1}$ for $[(S)-2]_{\mathrm{n}},[(S)-3]_{\mathrm{n}}$ and $[(S)-4]_{\mathrm{n}}$ respectively) are close to the expected value for one isolated ground state multiplet ${ }^{6} \mathrm{H}_{15 / 2}$ with $\mathrm{g}_{\mathrm{J}}=4 / 3$ (i.e. $14.17 \mathrm{~cm}^{3} \mathrm{~K} \mathrm{~mol}^{-}$ 1). ${ }^{75}$ On cooling down to $2 \mathrm{~K}$, the thermal depopulation of the ligand field sublevels leads to a monotonic decrease of the $\chi_{M}{ }^{T}$ product until the lowest reachable temperature $(2 \mathrm{~K})$. One could conclude that the dipolar interactions in the three $[(\boldsymbol{S})-2]_{n},[(S)-$ $3]_{n}$ and [(S)-4 $]_{n}$ compounds are weaker and/or of antiferromagnetic nature. The field-dependence of magnetization measured at $2 \mathrm{~K}$ is depicted in inset of the Figures 4 and S11 for all the compounds with a classic magnetic behaviour for a single isolated Dy(III) centre. The weak increase previously observed for $[(\mathbf{S})-\mathbf{1}]_{\mathrm{n}}$ (Fig. S11) is not observed for the others polymers.

Dynamic measurements. The dynamic measurement of the magnetic susceptibility for the three compounds $[(\boldsymbol{S})-2]_{n},[(S)-$ $3]_{\mathrm{n}}$ and $[(\boldsymbol{S})-4]_{\mathrm{n}}$ were done using immobilized crunched single crystals of dried samples. Under zero applied magnetic field, an out-of-phase signal was detected and its maxima is centred at about $8000 \mathrm{~Hz}$ for [(S)-2 $]_{\mathrm{n}}$ and $4000 \mathrm{~Hz}$ for [(S)-3 $]_{\mathrm{n}}$ while for [(S)$4]_{n}$ the maximum is localized at a frequency higher than 10000 $\mathrm{Hz}$ at $2 \mathrm{~K}$ (Figs. S11 and S12). The two [(S)-2 $]_{\mathrm{n}},[(S)-3]_{\mathrm{n}}$ compounds highlighted a frequency dependence of the inphase (Fig. S11) and out-of-phase (Fig. S12) signal of the magnetization allowing an analysis of the temperature variations (Tables S3 and S4) of the magnetic susceptibility in the framework of an extended Debye model (see Fig. S13 for a representative example). The thermal dependence of the relaxation time depicted in Figure 5 could be fitted in zero field with a combination of one thermally activated

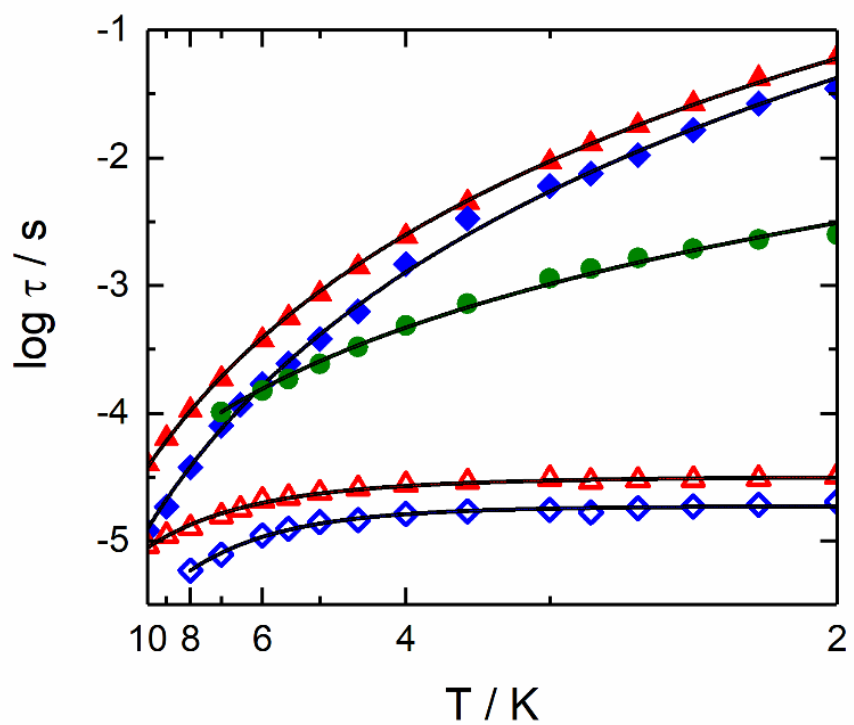

Fig. 5 Arrhenius plots of the temperature dependence of the relaxation time in a zero applied magnetic field for $[(S)-2]_{n}$ (open blue lozenges) and [(S)-3 $]_{n}$ (open red triangles) and under a 1000 Oe applied magnetic field for the three polymers [(S)-2 $]_{n}$ (full blue lozenges), $[(S)-3]_{n}$ (full red triangles) and [(S)-4 $]_{n}$ (full green disks). The black lines are the best-fitted curves using the parameters given in Table 1.
Table 1: Dynamic parameters of the different relaxation mechanism for the polymers.

\begin{tabular}{|c|c|c|c|}
\hline & Field (Oe) & Raman & QTM \\
\hline \multirow{3}{*}[(S)-2]{$_{\mathrm{n}}$} & 0 & $\begin{array}{c}\mathrm{C}=50.9(25) \mathrm{s}^{-1} \mathrm{~K}^{-\mathrm{n}} \\
\mathrm{n}=3.72(25)\end{array}$ & $\tau_{\text {TI }}=1.89(4) \times 10^{-5} \mathrm{~s}$ \\
\cline { 2 - 4 } & 1000 & $\begin{array}{c}\mathrm{C}=0.71(6) \mathrm{s}^{-1} \mathrm{~K}^{-\mathrm{n}} \\
\mathrm{n}=5.06(6)\end{array}$ & \\
\hline \multirow{3}{*}[(S)-3]{$_{\mathrm{n}}$} & 0 & $\begin{array}{c}\mathrm{C}=125(36) \mathrm{s}^{-1} \mathrm{~K}^{-\mathrm{n}} \\
\mathrm{n}=2.82(13)\end{array}$ & $\tau_{\tau \mathrm{Tl}}=3.23(6) \times 10^{-5} \mathrm{~s}$ \\
\cline { 2 - 4 } & 1000 & $\begin{array}{c}\mathrm{C}=0.69(2) \mathrm{s}^{-1} \mathrm{~K}^{-\mathrm{n}} \\
\mathrm{n}=4.59(2)\end{array}$ & \\
\hline$[(S)-4]_{\mathrm{n}}$ & 1000 & $\begin{array}{c}\mathrm{C}=48.8(41) \mathrm{s}^{-1} \mathrm{~K}^{-\mathrm{n}} \\
\mathrm{n}=2.73(6)\end{array}$ & \\
\hline
\end{tabular}

regime (Raman) and one thermally independent regime (QTM): $\tau^{-1}=C T^{n}+\tau_{T I^{-1}} .^{76}$ The best fits depicted in Figure 5 were obtained using the parameters of the Table 1 . The field dependence of the magnetic susceptibility was studied to cancel the fast magnetic relaxation attributed to the quantum tunnelling of the magnetization (QTM) (Figs. S14 and S15). The field variation of the relaxation time was plotted in Fig. S16 (Table S5-S7). From these plots, one can observed that at low magnetic field (200$400 \mathrm{Oe})$, multiple peaks are identified. Since for all samples a single crystallographically independent dysprosium was identified such behaviour could be attributed to significant intermolecular dipolar interactions. ${ }^{77}$ The 1000 Oe value was selected for all the samples as the best compromise values since the relaxation times at such applied field are close to the slowest relaxation time possible and the intensity of the out-ofphase signal is high. The application of the 1000 Oe magnetic field led to a shift of the out-of-phase component of the magnetic susceptibility at lower frequency and a frequency dependence of both in- (Fig. S17) and out-of-phase (Figs. S18 and S19) components of the ac magnetic susceptibility was observed. The temperature dependence of the relaxation time of the magnetic susceptibility was extracted fitting simultaneously $\chi_{M}{ }^{\prime}$ and $\chi_{M}{ }^{\prime \prime}$ with an extended Debye model (Tables S8-S10). For $[(\mathbf{S})-2]_{n}$ and $[(\mathbf{S})-3]_{n}$ at low temperatures, two contributions were taken into account in the fit (Fig. S20) while at higher temperatures only one contribution was considered. The (normalized) Cole-Cole plots were depicted in Fig. S21 and they show that the slow relaxing fractions represented the entire samples. The relaxation time of the magnetization $(\tau)$ for the low frequency (LF) contributions can be fitted using the thermally dependent Raman process only $\left(\tau^{-}\right.$ ${ }^{1}=\mathrm{CT}^{\mathrm{n}}$ ) (Fig. 5) while the $\log (\tau)$ vs T curve for the high frequency (HF) contribution was not fitted because it represents about 10$20 \%$ of the relaxing fraction (Figs. S22 and S23). The best fits are obtained with the parameters depicted in Table 1. For [(S)$4]_{n}$ the used of an extended Debye model considering two contributions at low temperatures failed because of the broad shape signal and the absence of clear shoulder. Thus only one contribution was considered to fit the $\log (\tau)$ vs T curve and the parameters of the best fit is given in Table 1. Under an applied magnetic field of 1000 Oe the following trend was observed $\tau\left([(S)-4]_{n}\right)<\tau\left([(S)-2]_{n}\right)<\tau\left([(S)-3]_{n}\right)<\tau\left([(S)-1]_{n}\right)^{48}$ for temperatures at which the under-energy barrier mechanisms (QTM and Raman) are efficient (below $5 \mathrm{~K}$ ). In other words, the 
partial hydrogenation and multiplication of the chiral centres could provoke a speeding of the magnetic relaxation. One might hypothesize that such chemical transformation leads to systems with respectively more vibrations ${ }^{78,79}$ and more bulky ligands leading to less suitable electronic distribution around the Dy(III) centre and thus both favouring the fast relaxation of the magnetization. Nevertheless the role played by the other structural differences such as distinct lattice and crystal packing couldn't rule out in the modulations of the magnetic relaxation times of the different polymers.

\section{Ab initio calculations}

$A b$ initio calculationsln order to explain the variation of magnetic relaxation time and to rationalize the magnetic properties of the polymers, SA-CASSCF/RASSI-SO calculations were performed on the model systems presented in Figure 6. The experimental thermal dependence of $\chi_{M} T$ and field dependence of the magnetizations were computed with the calculated energy splitting of the ${ }^{6} \mathrm{H}_{15 / 2}$ multiplet (Table S11) and the composition of the ground doublet states (Fig. 4). A good agreement with experiment is found for the magnetization curves at $2 \mathrm{~K}$ for all complexes confirming the correct description of the ground state of these systems. The ground states are mainly composed of $\pm 15 / 2$ doublet (94\% for $\left\{[(S)-2] \cdot 2\left(\mathrm{C}_{6} \mathrm{H}_{14}\right) \cdot \mathbf{0 . 5}\left(\mathrm{CH}_{2} \mathrm{Cl}_{2}\right)\right\}_{n}, 85 \%$ for $[(S)-3]_{n}$ and $82 \%$ for $[(S)-$ $4]_{n}$ leading to $\mathrm{g}_{\mathrm{z}}$ factor of $19.48,18.38$ and 18.28 for $\{[(S)-$ 2] $\left.\cdot 2\left(\mathrm{C}_{6} \mathrm{H}_{14}\right) \cdot \mathbf{0 . 5}\left(\mathrm{CH}_{2} \mathrm{Cl}_{2}\right)\right\}_{\mathrm{n}},[(S)-3]_{n}$ and $[(S)-4]_{n}$ respectively (Table S11). The main magnetic anisotropy axis appears perpendicular to the $\mathrm{P}=\mathrm{O}-\mathrm{Dy}-\mathrm{O}=\mathrm{P}$ direction and along the two hfac $^{-}$anions which are localized in the same plane. Such direction corresponds to the most charged orientation of the oblate Dy(III) ion coordination sphere (Fig. 6). However, a discrepancy with experimental data is found at lower temperatures on the $\chi_{M} T$ curves. For the partially hydrogenated systems $[(\boldsymbol{S})-3]_{n}$ and $[(\boldsymbol{S})-4]_{n}$, a faster decrease of the magnetic susceptibility is observed ending with a value of about $10.7 \mathrm{~cm}^{3}$ $\mathrm{K} \mathrm{mol}^{-1}$ at $2 \mathrm{~K}$, falling below the experimental value. This difference is due to the presence of several low energy excited states close in energy that are easily populated/depopulated upon heating/cooling (Table S11). While in the case of $\{[(S)-$ 2] $\left.\cdot \mathbf{2}\left(\mathrm{C}_{6} \mathrm{H}_{14}\right) \cdot \mathbf{0 . 5}\left(\mathrm{CH}_{2} \mathrm{Cl}_{2}\right)\right\}_{n}$, the larger splitting of the ground ${ }^{6} \mathrm{H}_{15 / 2}$ multiplet falls in a better agreement with experimental data. The energy gaps between the ground and the first excited states were calculated ranging from 23 to $64 \mathrm{~cm}^{-1}$, but the discrepancy with experimental data makes further interpretations hazardous. The modulation of the relaxation times in the series of one-dimensional compounds may be due to the slight crystal field variations around the Dy(III) centres.

Table 2. Energy splitting of the ${ }^{6} \mathrm{H}_{15 / 2}$ multiplet state with composition and $\mathrm{g}$ factor values for each Kramer Doublet (KD).

\begin{tabular}{|c|c|c|c|}
\hline \multicolumn{4}{|c|}{} \\
\hline$\left\{[(\mathbf{S})-\mathbf{2}] \cdot \mathbf{2}\left(\mathrm{C}_{6} \mathrm{H}_{14}\right) \cdot \mathbf{0 . 5}\left(\mathrm{CH}_{2} \mathrm{Cl}_{2}\right)\right\}_{\mathrm{n}}$ & 19.48 & $94 \% \pm 15 / 2$ & $\Delta\left(\mathrm{cm}^{-1}\right)$ \\
\hline$[(\mathbf{S})-3]_{\mathrm{n}}$ & 18.38 & $85 \% \pm 15 / 2$ & 64 \\
\hline$[(\boldsymbol{S})-4]_{\mathrm{n}}$ & 18.28 & $82 \% \pm 15 / 2$ & 23 \\
\hline
\end{tabular}
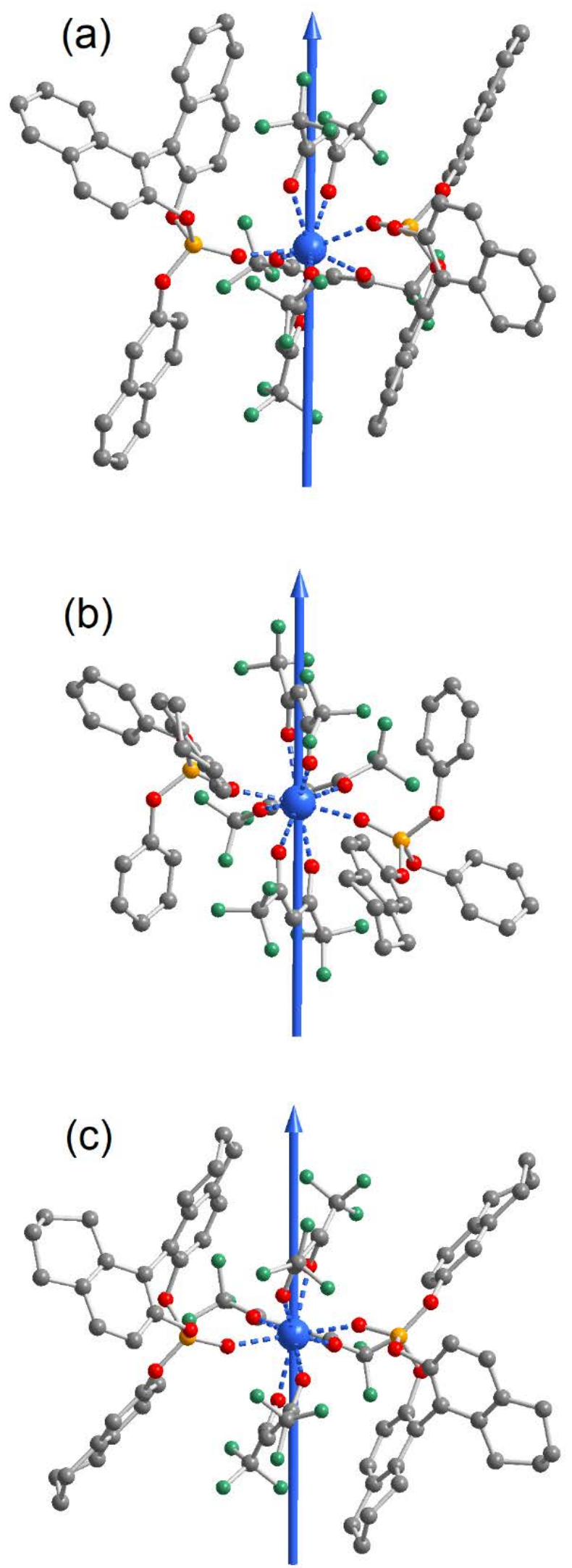

Fig. 6 Representation of the orientations of the computed principal magnetic axis for $\left\{[(S)-2] \cdot 2\left(\mathrm{C}_{6} \mathrm{H}_{14}\right) \cdot 0.5\left(\mathrm{CH}_{2} \mathrm{Cl}_{2}\right)\right\}_{\mathrm{n}}(\mathrm{a}),[(\mathrm{S})-3]_{\mathrm{n}}(\mathrm{b})$ and $[(\mathrm{S})-4]_{\mathrm{n}}(\mathrm{c})$. 


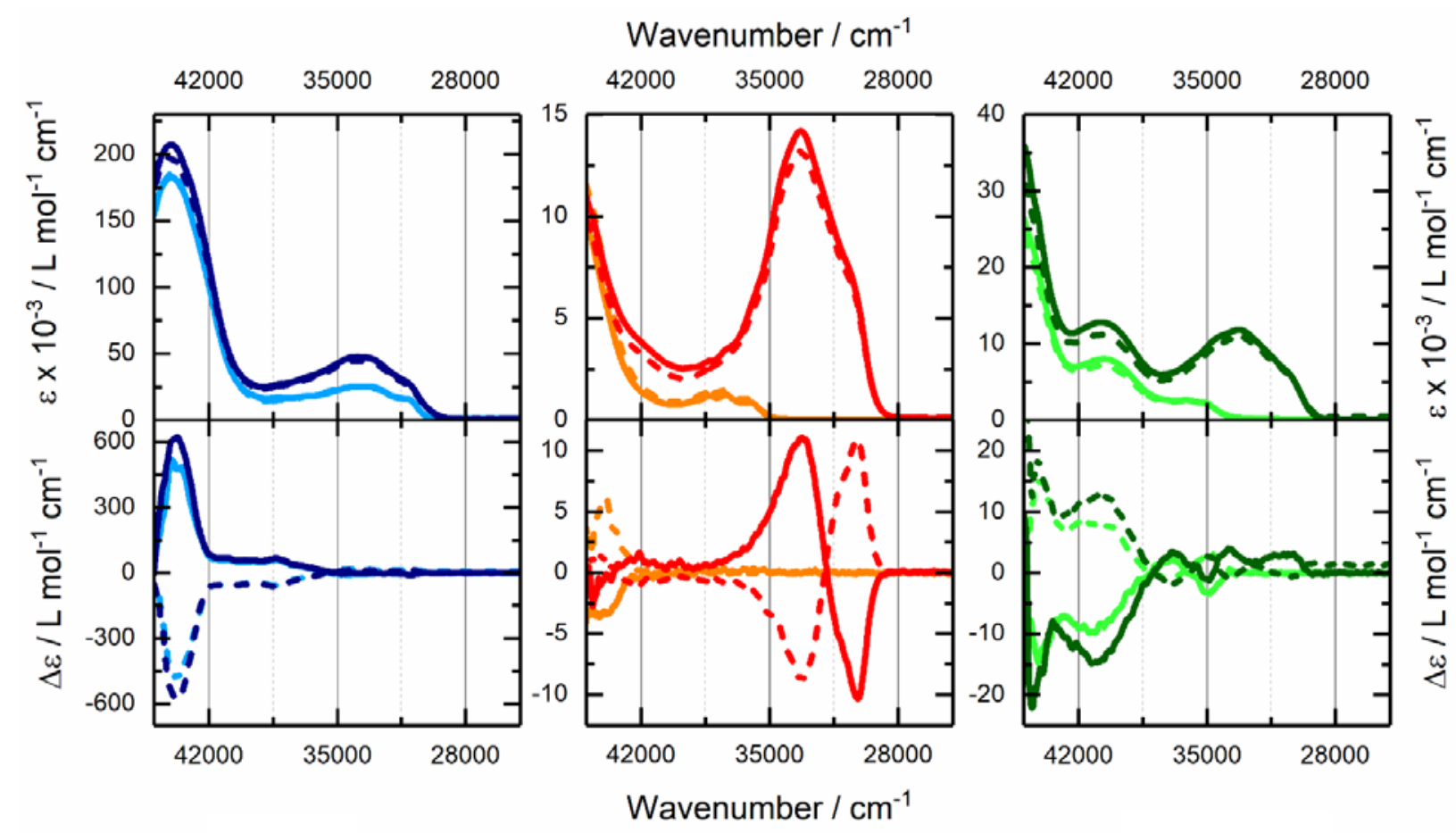

Fig. 7 Experimental UV-visible absorption (above) and $\mathrm{ECD}$ (below) spectra in $\mathrm{CH}_{2} \mathrm{Cl}_{2}$ solution (left) at $\mathrm{C}=1 \times 10^{-5}$ mol. $\mathrm{L}^{-1}$ for $(S)-\mathrm{L}^{2}$ (light blue line), $(R)$ - $\mathrm{L}^{2}$ (dashed light blue line), [(S)-

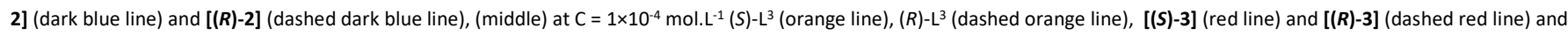
(right) at $\mathrm{C}=5 \times 10^{-5} \mathrm{~mol}^{-L^{-1}}$ for $(S)-\mathrm{L}^{4}$ (light green line), $(R)-\mathrm{L}^{4}$ (dashed light green line), [(S)-4] (dark green line) and [( $\left.\left.R\right)-4\right]$ (dashed dark green line).

\section{Photo-physical properties}

Absorption and Electronic Circular Dichroism (ECD). The UVvisible absorption properties of the free ligands $(S / R)-L^{2},(S / R)$ $\mathrm{L}^{3}$ and $(S / R)-\mathrm{L}^{4}$ have been measured at room temperature in $\mathrm{CH}_{2} \mathrm{Cl}_{2}$ solution (Fig. 7) and rationalized by TD-DFT (Tables S1215). The experimental absorption curves for the two enantiomers of each ligand are depicted in Fig. 7. They are composed of broad bands localized at the intermediate energy range of $30-40000 \mathrm{~cm}^{-1}$ and at high energy (above $43-45000 \mathrm{~cm}$ 1) which are mainly attributed to $\pi-\pi^{*}$ transitions of the binaphtyl-like moieties. The intermediate energy bands for the

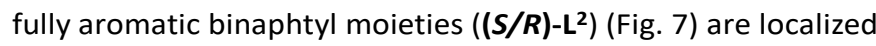
at lower energy (about $34000 \mathrm{~cm}^{-1}$ ) than for the partially hydrogenated ones $\left((S / R)-L^{3}\right.$ and $\left.(S / R)-L^{4}\right)$ (Fig. 7). Such observation is in agreement with the calculated excitation energies (Tables S12-15). It is worth to notice that the highest energy excitation is very intense for $(S / R)$ - $\mathbf{L}^{\mathbf{2}}$ compared to the other ligands because of the presence of multiple aromatic binaphtyl moieties. Based on previous studies, it is known that such polymers are likely to rearrange into monomers in solution. ${ }^{45,48}$ Thus $\mathrm{n}$ was taken equal to 1 for the formula of the compounds for UV-vis absorption ECD spectroscopies in solution. The experimental absorption spectra for complexes [(S/R)-2], [(S/R)-3] and [(S/R)-4] are similar than those for free ligand except that an additional intense excitation appeared at $33000 \mathrm{~cm}^{-1}$ due to the $\pi-\pi^{*}$ transitions of the hfac' anions (Fig. 7). ${ }^{80}$ The enantiomeric nature of the complexes in $\mathrm{CH}_{2} \mathrm{Cl}_{2}$ solution was confirmed by electronic circular dichroism (ECD) measurements performed at room temperature (Fig. 7). Cotton effect of opposite signs is observed for each enantiomer on the mirror-symmetrical dichroism spectra. The ECD contributions correspond to the absorption bands attributed to the ligands. In other words the ECD spectra can be attributed to the sole excitonic coupling between the $\pi-\pi^{*}$ transitions of the naphtyl groups. ${ }^{81-83}$ The ECD signals are more intense for the fully aromatic binaphtyl moieties (around $600 \mathrm{~L} \mathrm{~mol}^{-1} \mathrm{~cm}^{-1}$ for $[(S / R)$ 2]) (Fig. 7a) than for the partially hydrogenated ones (10-20 L $\mathrm{mol}^{-1} \mathrm{~cm}^{-1}$ for $[(S / R)-3]$ and [(S/R)-4]) (Figs. 7b and 7c) because the most intense ECD signals are expected at higher energy (out of our experimental window). It is worth to notice that the ECD signal for $[(S / R)-1]$ was found around $100 \mathrm{~L} \mathrm{~mol}^{-1} \mathrm{~cm}^{-1}$ in agreement with previous observations. One more observation is the exaltation of the ECD signal centred at lower energy $\left(34000 \mathrm{~cm}^{-1}\right)$ for $[(S / R)-3]$ due to the coordination of the achiral $\mathrm{Dy}(\mathrm{hfac})_{3}$ unit as already observed for $[(S / R)-1]^{48}$ while such effect is not observed for $[(S / R)-2]$ and $[(S / R)-4]$. One could conclude that the exaltation of the low-energy ECD signals only occurred for single binaphtyl-like ligands because they might be structurally more affected by the metal coordination in solution.

Luminescence. Emission properties have been studied for the three $[(S)-2]_{n},[(S)-3]_{n}$ and $[(S)-4]_{n}$ polymers in solid-state at 10 $\mathrm{K}$. While the light excitation of the samples induced ${ }^{4} \mathrm{~F}_{9 / 2} \rightarrow{ }^{6} \mathrm{H}_{\mathrm{J} / 2}$ (J ranging from 9/2 to 15/2) Dy(III) -centered luminescence for $[(S)-3]_{n}$ (Fig. S24) and [(S)-4 $]_{n}$ (Fig. S25), no visible Dy(III) emission was detected for $[(\boldsymbol{S})-\mathbf{2}]_{n}$. The excitation spectra are 
provided in Figs. S26 and S27. The Y(III) analogues of the polymers were irradiated in solid-state at $77 \mathrm{~K}$ leading to phosphorescence of the ligands (Fig. S28) with a long lifetime of $0.71 \mathrm{~s}$ for $[(S)-1]_{n}, 0.41 \mathrm{~s}$ for $[(S)-2]_{n}, 0.46 \mathrm{~s}$ for $[(S)-3]_{\mathrm{n}}$ and 0.43 $\mathrm{s}$ for $[(S)-4]_{\mathrm{n}}$ (Fig. S29). The shape and energy of the triplet state are similar for the three $Y(I I I)$ analogues of the emissive $[(S)-1]_{n}$, $[(S)-3]_{n}$ and $[(S)-4]_{n}$ polymers while it is clearly different for the non-emissive $[(\boldsymbol{S})-2]_{\mathrm{n}}$. Such observation might explain why [(S)$2]_{n}$ is not emissive. For the three others polymers, the energy of the triplet state of the ligand (around $21-22000 \mathrm{~cm}^{-1}$ ) is suitable for using the ligand $L^{1}, L^{3}$ and $L^{4}$ as organic chromophore for the sensitization of the visible Dy(III) luminescence through antenna effect. To give more insight to the origin of the non-emissive $[(S)-2]_{n}$ polymer, Density Functional Theory (DFT) calculations were performed for the free ligands $L^{2}, L^{3}$ and $L^{4}$. Such calculations demonstrated that for $\mathrm{L}^{3}$ and $\mathrm{L}^{4}$, the lowest-energy excited triplet state is localized at higher energy than the emissive levels of the Dy(III) while for $\mathrm{L}^{2}$ this excited triplet state is lower in energy (Table S16) due to its more extended $\pi$ system so it could quench the visible Dy(III) emission.

\section{Wavenumber $/ \mathrm{cm}^{-1}$}

2160021200208002040020000

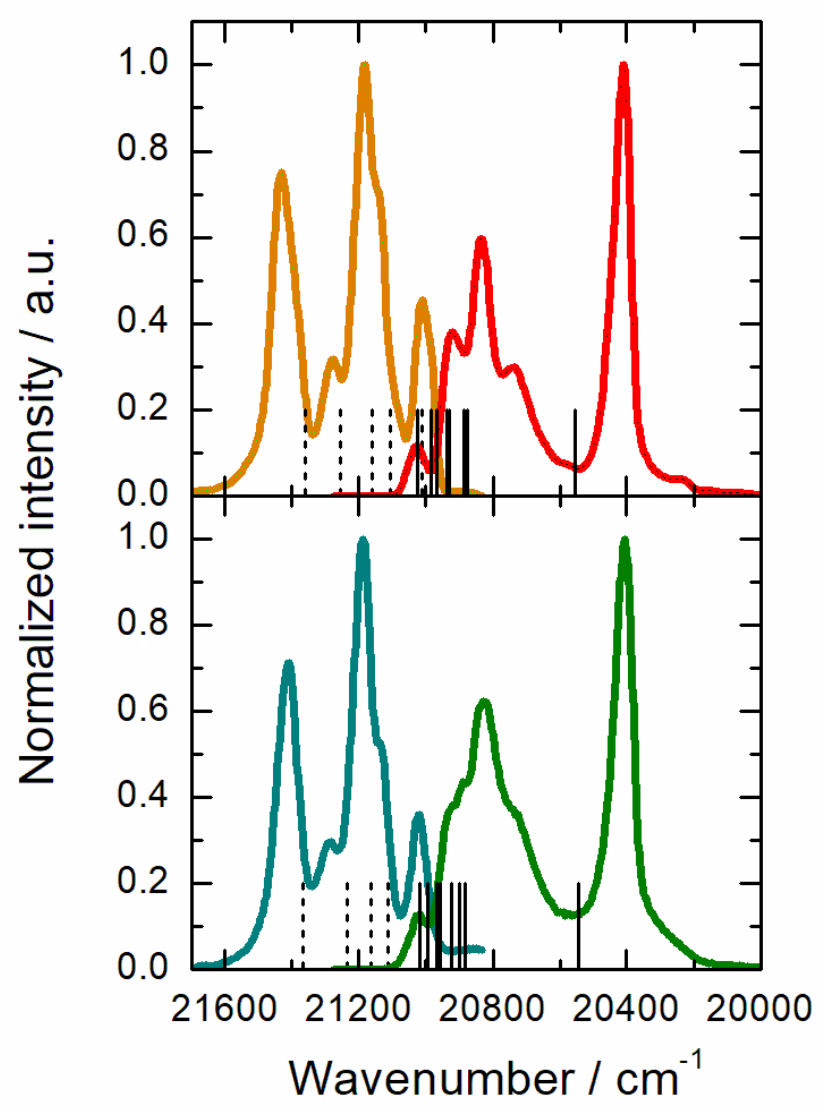

Fig. 8. Excitation spectra (orange line for $[(S)-3]_{n}(a)$ and turquoise line for $\left.[(S)-4]_{n}\right)(b)$ and emission spectra (red line for $[(S)-3]_{n}(a)$ and green line for $\left.[(S)-4]_{n}\right)$ at $10 \mathrm{~K}(b)$ with the calculated energy splitting for the ${ }^{7} \mathrm{~F}_{9 / 2}$ (dashed vertical sticks) and ${ }^{6} \mathrm{H}_{15 / 2}$ (vertical sticks) levels for an irradiation energy of $29400 \mathrm{~cm}^{-1}(340 \mathrm{~nm})$ for [(S)-3 $]_{\mathrm{n}}$ and $28570 \mathrm{~cm}$ ${ }^{1}(350 \mathrm{~nm})$ for $[(S)-4]_{\mathrm{n}}$.
It is well-known since the pioneer work of Sessoli and coll. ${ }^{84}$ that magneto-structural correlation can be done between magnetic properties and experimental luminescence for a wide selection of lanthanide ions. ${ }^{20,21,85-89}$ Thus, zooms of the highest-energy ${ }^{4} \mathrm{~F}_{9 / 2} \rightarrow{ }^{6} \mathrm{H}_{15 / 2}$ emissions are depicted in Figure 8 for $[(\boldsymbol{S})-3]_{n}$ and $[(S)-4]_{n}$ in association with their excitation spectra and both compared to the computed energy splitting. Such magnetostructural correlation was previously done by some of us for $[(S)-1]_{n} \cdot{ }^{40}$ A Boltzmann population calculation starting from the experimental excitation spectrum supported the fact that at 10 $\mathrm{K}$ only the ground $\mathrm{M}_{\mathrm{J}}$ state of the ${ }^{7} \mathrm{~F}_{9 / 2}$ level is populated. Thus eight emission lines are expected for the ${ }^{4} \mathrm{~F}_{9 / 2} \rightarrow{ }^{6} \mathrm{H}_{15 / 2}$ transition. Nevertheless, five emission lines could be identified (Fig. 8). The calculation at the CASSCF level gave the energy splitting for the ${ }^{6} \mathrm{H}_{15 / 2}$ ground state (black sticks on Fig. 8). Although the calculations tend to underestimate the energy splitting of the ground state ${ }^{6} \mathrm{H}_{15 / 2}$ multiplet, the results allow a qualitative description of the shouldered peak laying around $20800 \mathrm{~cm}^{-1}$ corresponding to the gathering of the lowest energy states close in energy and the high intensity peak at about $20400 \mathrm{~cm}^{-1}$ attributed to the last excited doublet of the ${ }^{6} \mathrm{H}_{15 / 2}$ multiplet. The computed energy barrier is $59 \mathrm{~K}$ and $33 \mathrm{~K}$ for [(S)$3]_{\mathrm{n}}$ and $[(S)-4]_{\mathrm{n}}$ highlighting a faster relaxation for $[(S)-4]_{\mathrm{n}}$ than $[(\boldsymbol{S})-3]_{n}$, as observed experimentally. In case of $[(\boldsymbol{S})-4]_{n}$, the resolution of the experimental emission spectrum is lower than $[(S)-3]_{n}$ and such experimental energy gap is more difficult to identify.

\section{Conclusions}

In this paper, six pure enantiomers of one-dimensional polymers of $\mathrm{Dy}(\mathrm{III})$ involving $\mathrm{BINOL}$ derived bisphosphate of formula $\quad\left\{\left[\mathrm{Dy}(\mathrm{hfac})_{3}\left(\mathrm{~S}-\mathrm{L}^{2}\right)\right] \cdot 0.5\left(\mathrm{CH}_{2} \mathrm{Cl}_{2}\right) \cdot 2\left(\mathrm{C}_{6} \mathrm{H}_{14}\right)\right\}_{\mathrm{n}} \quad\{[(\mathrm{S})$ 2] $\left.\cdot 2\left(\mathrm{C}_{6} \mathrm{H}_{14}\right) \cdot 0.5\left(\mathrm{CH}_{2} \mathrm{Cl}_{2}\right)\right\}_{\mathrm{n}}$ and $\left\{\left[\mathrm{Dy}(\mathrm{hfac})_{3}\left((R)-\mathrm{L}^{2}\right)\right] \cdot 2\left(\mathrm{C}_{6} \mathrm{H}_{14}\right)\right\}_{\mathrm{n}}\{[(R)-$ 2] $\left.\cdot 2\left(\mathrm{C}_{6} \mathrm{H}_{14}\right)\right\}_{n}, \quad\left[\mathrm{Dy}(\mathrm{hfac})_{3}\left((S / R)-L^{3}\right)\right]_{\mathrm{n}} \quad\left([(S / R)-3]_{\mathrm{n}}\right) \quad$ and $\left[\mathrm{Dy}(\mathrm{hfac})_{3}\left((S / R)-L^{4}\right)\right]_{\mathrm{n}}\left([(S / R)-4]_{\mathrm{n}}\right)$ as well as their $(S)$ yttrium analogues are reported. Their $\mathrm{X}$-ray diffraction structures revealed that the chains are built by bridging the $\mathrm{Dy}(\mathrm{hfac})_{3}$ units ( hfac $^{-}=1,1,1,5,5,5$-hexafluoroacetylacetonate) with the $\mathrm{L}^{2-4}$ ligands through the coordination of the $\mathrm{P}=\mathrm{O}$ chemical group of the phosphate.

The polymers displayed Single-Molecule Magnet behavior with magnetization relaxing through Raman and Quantum Tunnelling (in zero field) processes. The degree of aromaticity as well as the number of chiral centres induced electronic distribution modification which might be one of the reason of the variation in the SMM performances which have been studied by CASSCF calculations.

While $(S)-\mathrm{L}^{2}$ led to a quenching of the visible Dy(III) luminescence because of peculiar ligand-centred emission and low-energy excited triplet state, the other chiral ligands sensitized it by antenna effect allowing a correlation between the experimental luminescence at $10 \mathrm{~K}$ and magnetic data. The nature of the ligands induced also modification in the chiroptical properties with strong enhancement of the electronic circular dichroism signal at low energy range for $[(S / R)-3]$ but not for $[(S / R)-2]$ and $[(S / R)-4]$. 
This work highlighted the importance of the nature of the ligand to adjust the performances of multiple properties systems such as chiral luminescent SMM and paves the route to the observation of Dy(III) circularly polarized luminescence.

\section{Conflicts of interest}

There are no conflicts to declare.

\section{Acknowledgements}

This work was supported by the CNRS, Université de Rennes 1 and the European Commission through the ERC-CoG 725184 MULTIPROSMM (project n. 725184). B.L.G. and V.M. thank the French GENCI/IDRIS-CINES centre for high-performance computing resources. Part of this work has been performed using the Spectroscopies-DCTP core facility (UMS Biosit, Université de Rennes 1- Campus de Villejean- 35043 RENNES Cedex, FRANCE).

\section{Notes and references}

1 R. Sessoli, H. L. Tsai, A. R. Schake, S. Y. Wang, J. B. Vincent, K. Folting, D. Gatteschi, G. Christou and D. N. Hendrickson, Highspin molecules: [Mn12O12(O2CR)16(H2O)4]. J. Am. Chem. Soc., 1993, 115, 1804-1816.

2 R. Sessoli, D. Gatteschi, A. Caneschi and M. A. Novak, Magnetic bistability in a metal-ion cluster. Nature, 1993, 365, 141-143.

3 M. Mannini, F. Pineider, P. Sainctavit, C. Danieli, E. Otero, C. Sciancalepore, A. M. Talarico, M.-A. Arrio, A. Cornia, D. Gatteschi and R. Sessoli, Magnetic memory of a singlemolecule quantum magnet wired to a gold surface. Nat. Mater., 2009, 8, 194-197.

4 S. Thiele, F. Balestro, R. Ballou, S. Klyatskaya, M. Ruben and W. Wernsdorfer, Electrically driven nuclear spin resonance in single-molecule magnets. Science, 2014, 344, 1135-1138.

5 K. S. Pedersen, A.-M. Ariciu, S. McAdams, H. Weihe, J. Bendix, F. Tuna and S. Piligkos, Toward Molecular $4 \mathrm{f}$ Single-lon Magnet Qubits, J. Am. Chem. Soc., 2016, 138, 5801-5804.

6 M. Ganzhorn, S. Klyatskaya, M. Ruben and W. Wernsdorfer, Strong spin-phonon coupling between a single-molecule magnet and a carbon nanotube nanoelectromechanical system. Nat. Nanotechnol., 2013, 8, 165-169.

7 M. Urdampilleta, S. Klyatskaya, J.-P. Cleuziou, M. Ruben and W. Wernsdorfer, Supramolecular spin valves. Nat. Mater., 2011, 10, 502-506.

8 D. N. Woodruf, R. E. P. Winpenny and R. A. Layfield, Lanthanide Single-Molecule Magnets. Chem. Rev., 2013, 113 5110-5148.

9 N. Ishikawa, M. Sugita, T. Ishikawa, S. Koshihara and Y. Kaizu, Lanthanide Double-Decker Complexes Functioning as Magnets at the Single-Molecular Level. J. Am. Chem. Soc., 2003, 125, 8694-8695.

10 D. T. Thielemann, M. Klinger, T. J. A. Wolf, Y. Lan, W. Wernsdorfer, M. Busse, P. W. Roesky, A. N. Unterreiner, A. K. Powell, P. C. Junk and G. B. Deacon, Novel Lanthanide-Based Polymeric Chains and Corresponding Ultrafast Dynamics in Solution. Inorg. Chem., 2011, 50, $11990-12000$.

11 L. Bogani, C. Sangregorio, R. Sessoli and D. Gatteschi, Molecular Engineering for Single-Chain-Magnet Behavior in a One-Dimensional Dysprosium-Nitronyl Nitroxide Compound. Angew. Chem. Int. Ed., 2005, 44, 5817-5821.
12 Y. Z. Zheng, Y. H. Lan, W. Wernsdorfer, C. E. Anson and A. K. Powell, Polymerisation of the Dysprosium Acetate Dimer Switches on Single-Chain Magnetism. Chem. Eur. J., 2009, 15, $12566-12570$.

13 Y.-G. Huang, X.-T. Wang, F.-L. Jiang, S. Gao, M.-Y. Wu, Q. Gao, W. Wei and M.-C. Hong, Cobalt-Lanthanide Coordination Polymers Constructed with Metalloligands: A Ferromagnetic Coupled Quasi-1D Dy ${ }^{3+}$ Chain Showing Slow Relaxation. Chem. Eur. J., 2008, 14, 10340-10347.

14 N. Saleh, C. Shen and J. Crassous, Helicene-based transition metal complexes: synthesis, properties and applications. Chem. Sci., 2014, 5, 3680-3694 and references therein.

15 X.-L. Li, C.-L. Chen, H.-P. Xiao, A.-L. Wang, C.-M. Liu, X. Zheng, L.-J. Gao, X.-G. Yanga and S.-M. Fang, Luminescent, magnetic and ferroelectric properties of noncentrosymmetric chain-like complexes composed of nine-coordinate lanthanide ions. Dalton Trans., 2013, 42, 15317-15325.

16 J. Long, R. Vallat, R. A. S. Ferreira, L. D. Carlos, F. A. Almeida Paz, Y. Guari and J. Larionova, A bifunctional luminescent single-ion magnet: towards correlation between luminescence studies and magnetic slow relaxation processes. Chem. Commun. 2012, 48, 9974-9976.

17 F. Pointillart, B. Le Guennic, T. Cauchy, S. Golhen, O. Cador, O. Maury and L. Ouahab, A Series of Tetrathiafulvalene-Based Lanthanide Complexes Displaying Either Single Molecule Magnet or Luminescence-Direct Magnetic and Photo-Physical Correlations in the Ytterbium Analogue. Inorg. Chem. 2013, 52, 5978-5990.

18 M. Ren, S.-S. Bao, B.-W. Wang, R. A. S. Ferreira, L.-M. Zheng and L. D. Carlos, Lanthanide phosphonates with pseudo-D5h local symmetry exhibiting magnetic and luminescence bifunctional properties. Inorg. Chem. Front. 2015, 2, 558-566.

19 J. Long, E. Mamontova, V. Freitas, D. Luneau, V. Vieru, L. F. Chibotaru, R. A. S. Ferreira, G. Félix, Y. Guari, L. D. Carlos and J. Larionova, Study of the influence of magnetic dilution over relaxation processes in a $\mathrm{Zn} / \mathrm{Dy}$ single-ion magnet by correlation between luminescence and magnetism. RSC Adv., 2016, 6, 108810-108818.

20 G. Brunet, R. Marin, M. Monk, U. Resch-Genger, D. A. Galico, F. A. Sigoli, E. A. Suturina, E. Hemmer and M. Murugesu, Exploring the dual functionality of an ytterbium complex for luminescence thermometry and slow magnetic relaxation. Chem. Sci., 2019, 10, 6799-6808.

21 J. H.; Jia, Q.-W. Li, Y.-C. Chen, J.-L. Liu and M.-L. Tong, Luminescent single-molecule magnets based on lanthanides: Design strategies, recent advances and magneto-luminescent studies. Coord. Chem. Rev., 2019, 378, 365-381.

22 R. Marin, G. Brunet and M. Murugesu, Angew. Chem. Int. Ed. 2020, doi.org/10.1002/anie.201910299.

23 D. Guettas, F. Gendron, G. Fernandez Garcia, F. Riobé, T. Roisnel, O. Maury, G. Pilet, O. Cador and B. Le Guennic, Chem. Eur. J. 2020, 26, 4389-4395.

24 B. Casanovas, S. Speed, M. S. El Fallah, R. Vicente, M. FontBardia, F. Zinna and L. Di Bari, Chiral dinuclear Ln(III) complexes derived from $S$ - and R-2-(6-methoxy-2naphthyl)propionate. Optical and magnetic properties. Dalton Trans., 2019, 48, 2059-2067.

25 D.-P. Li, T.-W. Wang, C.-H. Li, D.-S. Liu, Y.-Z. Li and X.-Z. You, Single-ion magnets based on mononuclear lanthanide complexes with chiral Schiff base ligands $\left[\mathrm{Ln}(\mathrm{FTA})_{3} \mathrm{~L}\right](\mathrm{Ln}=\mathrm{Sm}$, Eu, Gd, Tb and Dy). Chem. Commun., 2010, 46, 2929-2931.

26 X.-L. Li, C.-L. Chen, Y.-L. Gao, C.-M. Liu, X.-L. Feng, Y.-H. Gui and S-M. Fang, Modulation of Homochiral DyllI Complexes: SingleMolecule Magnets with Ferroelectric Properties. Chem. Eur. J., 2012, 18, 14632-14637.

27 X.-L. Li, C.-L. Chen, H.-P. Xiao, A.-L. Wang, C.-M. Liu, X. Zheng, L.-J. Gao, X.-G. Yang and S.-M. Fang, Luminescent, magnetic and ferroelectric properties of noncentrosymmetric chain-like 
complexes composed of nine-coordinate lanthanide ions. Dalton Trans., 2013, 42, 15317-15325.

28 J. Long, J. Rouquette, J.-M. Thibaud, R. A. R. Ferreira, L. D. Carlos, B. Donnadieu, V. Vieru, L. F. Chibotaru, L. Konczewicz, J. Haines, Y. Guari and J. Larionova, A High-Temperature Molecular Ferroelectric Zn/Dy Complex Exhibiting Single-lonMagnet Behavior and Lanthanide Luminescence. Angew. Chem. Int. Ed., 2015, 54, 2236-2240.

29 X.-L. Li, M. Hu, Z. Yin, C. Zhu, C.-M. Liu, H.-P. Xiao and S. Fang, Enhancement single-ion magnetic and ferroelectric properties of mononuclear Dy(III) enantiomeric pairs through the coordination role of chiral ligands. Chem. Commun., 2017, 53, 3998-4001.

30 K. Wang, S. Zeng, H. Wang, J. Dou and J. Jiang, Magneto-chiral dichroism in chiral mixed (phthalocyaninato)(porphyrinato) rare earth triple-decker SMMs. Inorg. Chem. Front., 2014, 1, 167-171.

31 K. Dhbaibi, L. Favereau and J. Crassous, Enantioenriched Helicenes and Helicenoids Containing Main-Group Elements (B, Si, N, P). Chem. Rev., 2019, 119, 8846-8953.

32 L. Polavarapu Prasad, J. He, J. Crassous and K. Ruud, Absolute configuration of $\mathrm{C} 76$ from optical rotatory dispersion. ChemPhysChem, 2005, 6, 2535-2540.

33 Y. Yang, R. C. da Costa, M. J. Fuchter and A. J. Campbell, Circularly polarized light detection by a chiral organic semiconductor transitor. Nat. Photonics, 2013, 7, 634-638.

34 D. Schweinfurth, M. Zalibera, M. Kathan, C. Shen, M. Mazzolini, N. Trapp, J. Crassous, G. Gescheidt and F. Diederich, Helicene Quinones: Redox-Triggered Chiroptical Switching and Chiral Recognition oft he Semiquinone Radical Anion Lithium Salt by Electron Nuclear Double Resonance Spectroscopy. J. Am. Chem. Soc., 2014, 136, $13045-13052$.

35 F. Pointillart, J.-K. Ou-Yang, G. Fernandez Garcia, V. Montigaud, J. Flores Gonzalez, R. Marchal, L. Favereau, F. Totti, J. Crassous, O. Cador, L. Ouahab and B. Le Guennic. Tetrathiafulvalene-Based Helicene Ligand in the Design of a Dysprosium Field-Induced Single-Molecule Magnet. Inorg. Chem., 2019, 58, 52-56.

36 M. Galland, F. Riobé, J. Ouyang, N. Saleh, F. Pointillart, V. Dorcet, B. Le Guennic, O. Cador, J. Crassous, C. Andraud, C. Monnereau and $O$. Maury, Helicenic Complexes of Lanthanides: Influence of the f-Element on the Intersystem Crossing Efficiency and Competition between Luminescence and Oxyen Sensitization. Eur. J. Inorg. Chem., 2019, 118-125.

37 M. McCann, E. Murphy, C. Cardin and M. Convery, Reaction of ( \pm )-1,1'-binaphthyl-2,2'-diyl hydrogen phosphate $\{( \pm)$-phosH $\}$ with copper(II), cobalt(II) and iron(II) compounds; Identification by $x$-ray diffraction of $\left[\mathrm{Co}\left(\mathrm{CH}_{3} \mathrm{OH}\right)_{4}\left(\mathrm{H}_{2} \mathrm{O}\right)_{2}\right][(+)$ phos][(-)-phos]. $2 \mathrm{CH}_{3} \mathrm{OH} \cdot \mathrm{H}_{2} \mathrm{O}$. Polyhedron, 1991, 10, 27712777.

38 T. Hayano, T. Sakaguchi, H. Furuno, M. Ohba, H. Okawa and J. Inanaga, Novel Cerium(III)-(R)-BNP Complex as a Storable Chiral Lewis Acid Catalyst for the Enantioselective HeteroDiels-Alder Reaction. Chem. Letters, 2003, 32, 608-609.

39 H. Furuno, T. Hayano, T. Kambara, Y. Sugimoto, T. Hanamoto, Y. Tanaka, Y.-Z. Jin, T. Kagawa and J. Inanaga, Chiral rare earth organophosphates as homogeneous Lewis acid cataysts for the highly enantioselective hetero-Diels-Alder reactions. Tetrahedron, 2003, 59, 10509-10523.

$40 \mathrm{H}$. Furuno, T. Kambara, Y. Tanaka, T. Hanamoto, T. Kagawa and J. Inanaga, Highly enantioselective homogeneous catalysis of chiral rare earth phosphates in the hetero-DielsAlder reaction. Tetrahedron Lett., 2003, 44, 6129-6132.

$41 \mathrm{H}$. Furuno, T. Hanamoto, Y. Sugimoto and J. Inanaga, Remarkably High Asymmetric Amplification in the Chira Lanthanide Complex-Catalyzed Hetero-Diels-Alder Reaction: First Example of the Nonlinear Effect in $\mathrm{ML}_{3}$ System. Org. Lett., 2000, 2, 49-52.
42 S. Fukuzawa, K. Metoki and S. Esumi, Asymmetric Diels-Alder reactions in supercritical carbon dioxide catalyzed by rare earth complexes. Tetrahedron, 2003, 59, 10445-10452.

43 S. Suzuki, H. Furuno, Y. Yokoyama and J. Inanaga, Asymmetric fluorination of $\beta$-keto esters catalyzed by chiral rare earth perfluorinated organophosphates. Tetrahedron: asymmetry, 2006, 17, 504-507.

44 N. Hara, M. Okazaki, M. Shizuma, S. Marumoto, N. Tajima, M. Fujiki and Y. Imai, Swapping Circularly Polarised Luminescence of Eu(III)-Binaphthyl Hybridized Luminophore with and without Oxymethylene Spacer. ChemistrySelect, 2017, 2, 10317-10322.

45 N. Koiso, Y. Kitagawa, T. Nakanishi, K. Fushimi and Y. Hasegawa, Eu(III) Chiral Coordination Polymer with a Structural Transformation System. Inorg. Chem., 2017, 56, 5741-5747.

46 A. J. Jalilah, F. Asanoma and M. Fujiki, Unveiling controlled breaking of the mirror symmetry of $\mathrm{Eu}(\mathrm{fod})_{3}$ with $\alpha$-/ $\beta$-pinene and BINAP by circularly polarised luminescence (CPL), CPL excitation, and ${ }^{19} \mathrm{~F}-/{ }^{31} \mathrm{P}\left\{{ }^{1} \mathrm{H}\right\}-\mathrm{NMR}$ spectra and Mulliken charges. Inorg. Chem. Front., 2018, 5, 2718-2733.

47 M. Feng, B.-H. Lyu, M.-H. Wang, W.-W. Wu, Y.-C. Chen, G.-Z. Huang, W.-Q. Lin, S.-G. Wu, J.-L. Liu, M.-L. Tong, Chiral Erbium(III) Complexes: Single-Molecule Magnet Behavior, Chirality, and Nuclearity Control. Inorg. Chem. 2019, 58, 10694-10703.

48 C. A. Mattei, V. Montigaud, F. Gendron, S. Denis-Quanquin, V. Dorcet, N. Giraud, F. Riobé, G. Argouarch, O. Maury, B. Le Guennic, O. Cador, C. Lalli and F. Pointillart, Solid-State versus Solution Investigation of a Luminescent Chiral BINOL Derived Bisphosphate Single-Molecule Magnet, accepted.

49 A. Ngo Ndimba, T. Roisnel, G. Argouarch and C. Lalli, Harvesting New Chiral Phosphotriesters by Phosphorylation of BINOL and Parent Bis-phenols. Synthesis, 2019, 51, 865873.

50 M. F. Richardson, W. F. Wagner and D. E. Sands, Rare-earth trishexafluoroacetylacetonates and related compounds. J. Inorg. Nucl. Chem., 1968, 30, 1275-1289.

51 G. M. Sheldrick, SHELXT - Integrated space-group and crystalstructure determination, Acta Crystallogr.. Sect. A Found Adv., 2015, 71, 3-8.

52 G. M. Sheldrick, Crystal structure refinement with SHELXL, Acta Crystallogr. Sect. C, 2015, 71, 3-8.

53 A. L. Spek, Single-crystal structure validation with the program PLATON, J. Appl. Crystallogr., 2003, 36, 7-13.

54 M. J. Frisch, G. W. Trucks, H. B. Schlegel, G. E. Scuseria, M. A. Robb, J. R. Cheeseman, G. Scalmani, V. Barone, B. Mennucci, G. A. Petersson, et al. Gaussian 09 Revision, A.02; Gaussian Inc.: Wallingford, CT, USA, 2009.

55 J. P. Perdew, K. Burke and M. Ernzerhof, Genrelized Gradient Approximation Made Simple. Phys. Rev. Lett., 1996, 77, 38653868.

56 C. Adamo and V. Barone, Toward reliable density functional methods without adjustable parameters: The PBEO model. J. Chem. Phys., 1999, 110, 6158-6170.

$57 \mathrm{~F}$. Weigend and R. Ahlrichs, Balanced basis sets of split valence, triple zeta valence and quadruple zeta valence quality for $\mathrm{H}$ to Rn: Design and assessment of accuracy. Phys. Chem. Chem. Phys., 2005, 7, 3297-3305

58 J. Tomasi, B. Mennucci and R. Cammi, Quantum Mechanical Continuum Solvation Models. Chem. Rev., 2005, 105, 29993093.

59 M. Cossi and V. Barone, Time-dependent density functional theory for molecules in liquid solutions. J. Chem. Phys., 2001, 115, 4708-4717.

60 R. Improta, V. Barone, G. Scalmani and M. J. Frisch, A. StateSpecific Polarizable Continuum Model Time Dependent Density Functional Theory Method for Excited State 
Calculations in Solution. J. Chem. Phys., 2006, 125, 054103054109.

$61 \mathrm{M}$. Dolg, H. Stoll and H. Preuss, A combination of quasirelativistic pseudopotential and ligand field calculations for lanthanoid compounds. Theor. Chim. Acta., 1993, 85, 441450.

62 F. Aquilante, J. Autschbach, R. K. Carlson, L. F. Chibotaru, M. G. Delcey, L. De Vico, I. F. Galván, N. Ferré, L. M. Frutos, L. Gagliardi, M. Garavelli, A. Giussani, C. E. Hoyer, G. L. Manni, H. Lischka, D.-X. Ma, P. Malmqvist, T. Müller, A. Nenov, M. Olivucci, T. B. Pedersen, D. L. Peng, F. Plasser, B. Pritchard, M. Reiher, I. Rivalta, I. Schapiro, J. Segarra-Martí, M. Stenrup, D. G. Truhlar, L. Ungur, A. Valentini, S. Vancoillie, V. Veryazov, V. P. Vysotskiy, O. Weingart, F. Zapata and R. Lindh Molcas 8: New capabilities for multiconfigurational quantum chemical calculations across the periodic table. J. Comput. Chem., 2016, 37, 506-541.

63 B. O. Roos, P. R. Taylor and P. E. M. Siegbahn, A complete active space SCF method (CASSCF) using a density matrix formulated super- $\mathrm{Cl}$ approach. Chem. Phys., 1980, 48, 157173.

64 M. Douglas and N. M. Kroll, Quantum electrodynamical corrections to the fine structure of helium. Ann. Phys., 1974, 82, 89-155.

65 B. A. Hess, Applicability of the no-pair equation with freeparticle projection operators to atomic and molecular structure calculations. Phys. Rev. A, 1985, 32, 756-763.

66 B. A. Hess, Relativistic electronic-structure calculations employing a two-component no-pair formalism with externalfield projection operators. Phys. Rev. A, 1986, 33, 3742-3748.

67 A. Wolf, M. Reiher and B. A. Hess, The generalized DouglasKroll transformation. J. Chem. Phys., 2002, 117, 9215-9226.

68 P.-O. Widmark, P.-A. Malmqvist and B.-O. Roos, Density matrix averaged atomic natural orbital (ANO) basis sets for correlated molecular wave functions. Theor. Chim. Acta, 1990, 77, 291-306.

69 B. O. Roos, R. Lindh, P.-A Malmqvist, V. Veryazov and P.-O. Widmark, Main Group Atoms and Dimers Studied with a New Relativistic ANO Basis Set. J. Phys. Chem. A, 2004, 108, 28512858.

70 B. O. Roos, R. Lindh, P.-A. Malmqvist, V. Veryazov and P.-O. Widmark, New Relativistic ANO Basis Sets for Transition Meta Atoms. J. Phys. Chem. A, 2005, 109, 6575-6579.

71 P.-A. Malmqvist, B. O. Roos and B. Schimmelpfennig, The restricted active space (RAS) state interactionapproach with spin-orbit coupling. Chem. Phys. Lett., 2002, 357, 230-240.

$72 \mathrm{H}$. Bolvin, An Alternative Approach to the g-Matrix: Theory and Applications. ChemPhysChem, 2006, 7, 1575-1589.

73 L. F. Chibotaru and L. Ungur, $A b$ initio calculation of anisotropic magnetic properties of complexes. I. Unique definition of pseudospin Hamiltonians and their derivation. $J$. Chem. Phys., 2012, 137, 064112-22.

74 M. Llunell, D. Casanova, J. Cirera, P. Alemany and S. Alvarez, SHAPE Program for the Stereochemical Analysis of Molecular Fragments by Means of Continuous Shape Measures and Associated Tools; Departament de Quimica Fisica, Departament de Quimica Inorganica, and Institut de Quimica Teorica i Computacional - Universitat de' Barcelona, Barcelona, Spain.

75 O. Kahn, Molecular Magnetism, VCH: Weinhem, 1993.
76 J. M. Zadrozny, M. Atanasov, A. M. Bryan, C.-Y. Lin, B. D. Rekken, P. P. Power, F. Neese and J. R. Long, Slow magnetization dynamics in a series of two-coordinate iron(II) complexes. Chem. Sci., 2013, 4, 125-138.

77 L. T. A. Ho, L. F. Chibotaru, Intermolecular mechanism for multiple maxima in molecular dynamic susceptibility. Phys. Rev. B, 2018, 98, 174418.

78 F. Ortu, D. Reta, Y.-S; Ding, C. A. P. Goodwin, M. P. Gregson, E. J. L. McInnes, R. E. P. Winpenny, Y.-Z. Zheng, S. T. Liddle, D. P. Mills and N. F. Chilton, Studies of hysteresis and quantum tunnelling of the magnetisation in dysprosium(III) single molecule magnets. Dalton Trans., 2019, 48, 8541-8545.

79 L. Escalera, J. J. Baldovi, A. Gaita-Arino and E. Coronado, Design of high-temperature $f$-block molecular nanomagnets through the control of vibration-induced spin relaxation. Chem. Sci., 2020, 11, 1593-1598.

80 F. Pointillart, J. Jung, R. Berraud-Pache, B. Le Guennic, V. Dorcet, S. Golhen, O. Cador, O. Maury, Y. Guyot, S. Decurtins, S.-X. Liu and L. Ouahab, Luminescence and Single-Molecule Magnet Behavior in Lanthanide Complexes Involving a Tetrathiafulvalene-Fused Dipyridophenazine Ligand. Inorg. Chem., 2015, 54, 5384-5397.

81 G. Pescitelli, L. Di Bari and N. Berova, Conformational aspects in the studies of organic compounds by electronic circular dichroism. Chem. Soc. Rev., 2011, 40, 4603-4625.

82 N. Berova, L. Di Bari and G. Pescitelli, Conformational aspects in the studies of organic compounds by electronic circular dichroism. Chem. Soc. Rev., 2007, 36, 914-931.

83 L. Di Bari, G. Pescitelli and P. Salvadori, Conformational Study of 2,2'-Homosubsitututed 1,1'-Binaphthyls by Means of UV and CD Spectroscopy. J. Am. Chem. Soc., 1999, 121, 79988004.

84 G. Cucinotta, M. Perfetti, J. Luzon, M. Etienne, P. E. Car, A. Caneschi, G. Calvez, K. Bernot and R. Sessoli, Magnetic anisotropy in a dysprosium/DOTA single-molecule magnet: beyond simple magneto-structural correlations. Angew. Chem., Int. Ed., 2012, 51, 1606-1610.

85 M.-E. Boulon, G. Cucinotta, J. Luzon, C. Degl'Innocenti, M. Perfetti, K. Bernot, G. Calvez, A. Caneschi and R. Sessoli, Magnetic Anisotropy and Spin-Parity Effect Along the Series of Lanthanide Complexes with DOTA. Angew. Chem., Int. Ed., 2013, 52, 350-354.

86 F. Pointillart, B. Le Guennic, S. Golhen, O. Cador, O. Maury and L. Ouahab, A redox-active luminescent ytterbium based single molecule magnet. Chem. Commun., 2013, 49, 615-617.

87 F. Pointillart, B. Le Guennic, O. Cador, O. Maury and L. Ouahab, Lanthanide Ion and Tetrathiafulvalene-Based Ligand as a "Magic" Couple toward Luminescence, Single-Molecule Magnets, and Magnetostructural Correlations. Acc. Chem. Res., 2015, 48, 2834-2842.

88 M. Ren, S.-S. Bao, R. A. S. Ferreira, L.-M. Zheng and L. D. Carlos, A layered erbium phosphonate in pseudo- $D_{5 h}$ symmetry exhibiting field-tunable magnetic relaxation and optical correlation. Chem. Commun., 2014, 50, 7621-7624.

89 J. Long, Y. Guari, R. A. S. Ferreira, L. D. Carlos and J. Larionova, Recent advances in luminescent lanthanide based SingleMolecule Magnets. Coord. Chem. Rev., 2018, 363, 57-70. 